\title{
Duality in LNG tank-pressure behaviour and its relevance for ship-to-ship transfers to floating storage and regasification units
}

\author{
Maksym Kulitsa ${ }^{1}$, David A. $\operatorname{Wood}^{2 \oplus *}$ \\ ${ }^{1}$ Independent FSRU Operations Consultant, Odessa, Ukraine \\ ${ }^{2}$ DWA Energy Limited, Lincoln, United Kingdom
}

\author{
Keywords: \\ LNG \\ floating storage and regasification units \\ ship-to-ship transfers \\ LNG tank pressure influences \\ volume balances \\ predicting LNG tank pressure trends \\ saturated vapor pressure benchmark

\section{Cited as:} \\ Kulitsa, M., Wood, D.A. Duality in LNG \\ tank-pressure behaviour and its relevance \\ for ship-to-ship transfers to floating \\ storage and regasification units. Advances \\ in Geo-Energy Research, 2020, 4(1): \\ 54-76, doi: 10.26804/ager.2020.01.06.
}

\begin{abstract}
:
Floating storage and regasification units (FSRU) are in high demand globally forming a specialized and growing fleet of ships to service a steadily expanding liquified natural gas (LNG) industry. Ship-to-Ship (STS) LNG cargo transfers are an inevitable part of the FSRU day-to-day operating patterns. It is little more than a decade since FSRU operations began and a lack of knowledge persists concerning their relatively complex tank pressure behaviour during STS transfers. In this work, based on details from more than thirty STS operations, FSRU tank pressure trends and influencing factors are explained. The interactions between the vapor space and liquid LNG are strongly influenced by the thin surface film between those phases in an LNG tank. The saturated vapor pressure (SVP) of the LNG and the volumetric balance of gas and liquid movements in and out of the tank are also influential. These factors control the rate and extent of evaporation and condensation occurring at the surface film, thereby impacting tank pressure changes. This paper presents observations that reveal a duality in FSRU tank pressure behaviour that in over-pressured conditions allows tank pressure to rise significantly and rapidly. On the other hand, in under-pressured conditions tank pressure stabilizes at certain levels and inhibits significant reduction below those levels. Here, we explain the processes involved in determining FSRU tank pressure trends during STS transfers, and, based on observations of actual STS transfers, provide rules of thumb and empirical equations that can be used to estimate tank pressure behaviour in a range of operating conditions. These are supported by several generic cases of tank pressure, temperature and SVP trends reflecting the various tank scenarios commonly associated with routine operating patterns of FSRU during STS transfers. The principles described in this paper apply to LNG Carriers but tend to be disrupted by sloshing and wave movements also in the tanks during transit.
\end{abstract}

\section{Introduction}

Liquefied natural gas (LNG) ship-to-ship (STS) transfers are now a key and routine part of marine LNG operations (Kulitsa and Wood, 2017a). They are common for LNG carriers (LNGC) as well as an inherent part of Floating Storage and Regasification Units (FSRU) operations. A significant technological step forward for FSRU boil-off gas (BOG) handling equipment (Glomski and Michalski, 2011) has occurred in recent years that deals with BOG efficiently and minimises the usage of the gas combustion unit (GCU) or steam dump (SD). However, during STS transfers modern FSRU (DFDE type) often cannot avoid gas consumption in the GCU leading to cargo loss, due to the excessive tank-pressure increases.

Changes to the physical properties of LNG in containment tanks is controlled by the physical laws applicable to any condensed cryogenic gas in a closed system when the liquid phase is in contact with its vapor phase. LNG is stored in commercial large-scale containment tanks at its boiling temperature (about $-160{ }^{\circ} \mathrm{C}$ ) and pressure slightly above atmospheric pressure. The LNG in such tanks is not boiling in the way we associate with boiling water in a kettle; rather it is evaporating at various rates (convection boiling mode) from

${ }^{*}$ Corresponding author.

E-mail address: maksymkulitsa@gmail.com (M. Kulitsa); dw@dwasolutions.com (D.A. Wood). 


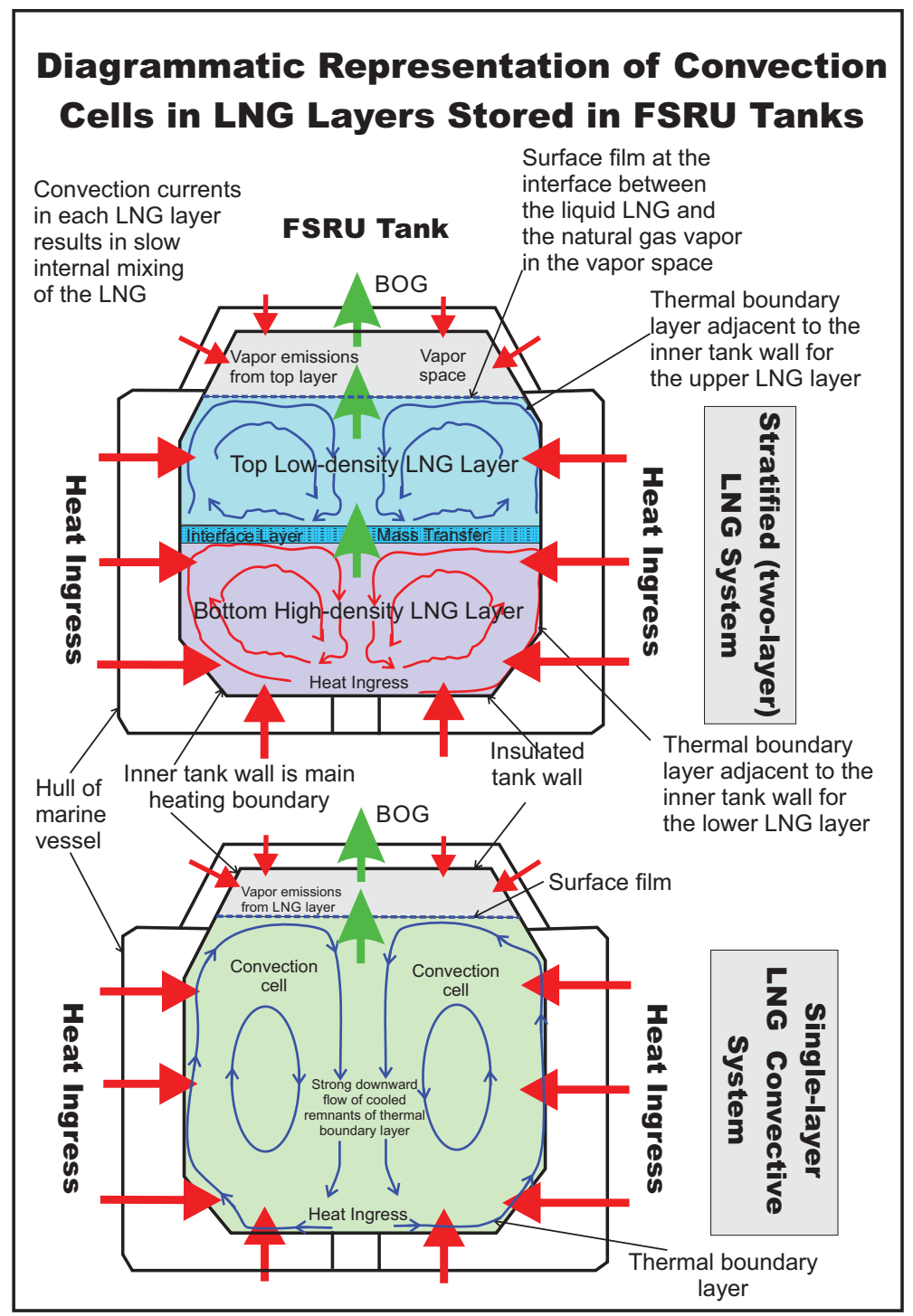

Fig. 1. Convective systems, layers and sub-layers in LNG stored within FSRU tanks (Kulitsa and Wood, 2018a).

the LNG liquid surface (liquid-gas interface only). The liquid LNG mass immediately adjacent to heating surfaces (e.g., tanks walls) is heated by heat ingress and becomes slightly less dense. This causes it to rise in the tank until it reaches the liquid surface (Kanazawa et al., 2004; Roh and Son, 2012; Scurlock, 2016). At that surface the excessive heat is released as a BOG "flash" into the tank vapor space (Kulitsa and Wood, 2018a). The liquid portion of LNG that has released the BOG flash is cooled by that event, thereby becoming denser and sinking towards the centre of the tank. This process sets-up convective currents and sub layers (Fig. 1) within the liquid portion of the LNG (Sha et al., 2018) that effectively maintain the LNG bulk mass at the same composition and temperature (i.e., a homogenous state).

The "thermal boundary sub-layer" is a feature associated with a fluid moving along a heated wall (Prandtl, 1905). In LNG tanks, it is dynamic and constantly moving in an upward direction along heating surfaces (i.e., a tank's inner boundary walls) until it reaches the LNG's liquid surface (Booth et al., 1974), where it turns and flows horizontally towards the tank centre. The two-dimensional flow of the thermal boundary layer can be described mathematically (Weyburne, 2006) with thickness and shape parameters and integrals of the temperature profile (Weyburne, 2017). It does this by moving underneath a thin LNG surface film. This film is the interface between the liquid and vapor space (Fig. 2). The LNG sub-layer then sinks towards the centre of tank as a downward stream. This sub-layer is always present and "on the move" carrying heat and mass with it. Significantly, it carries heat ingress through the tank walls to the surface film from which it dissipates, transferring "heat" or "cold" into the LNG bulk. This depends on the ratio of energy removed by BOG versus energy leaked in (Dimopoulis and Frangopoulous, 2008; Dobrota et al., 2013). The cross-sectional thickness of the thermal boundary sub-layer is a few millimetres and it is always immediately adjacent to the tank walls, except when it is flowing horizontal beneath the surface layer film. However, this heat and mass flow ultimately generates convective 


\section{Temperature Profiles of the LNG-Vapor Interface in an LNG Tank Depend on Prevailing Tank Pressure}

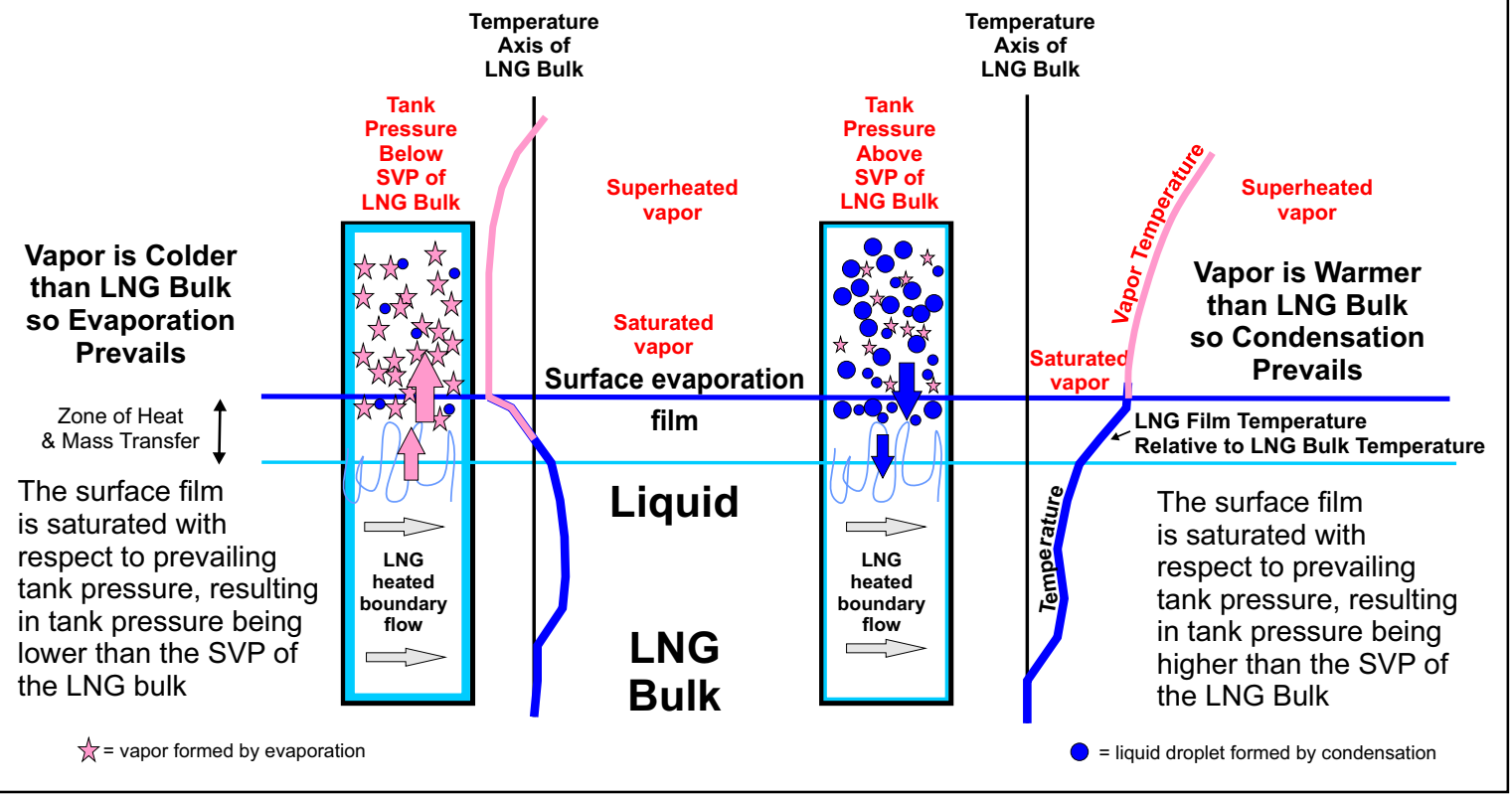

Fig. 2. Temperature profile across the evaporation film, first identified by Hashemi and Wesson (1971), depends on the prevailing conditions in an LNG tank.

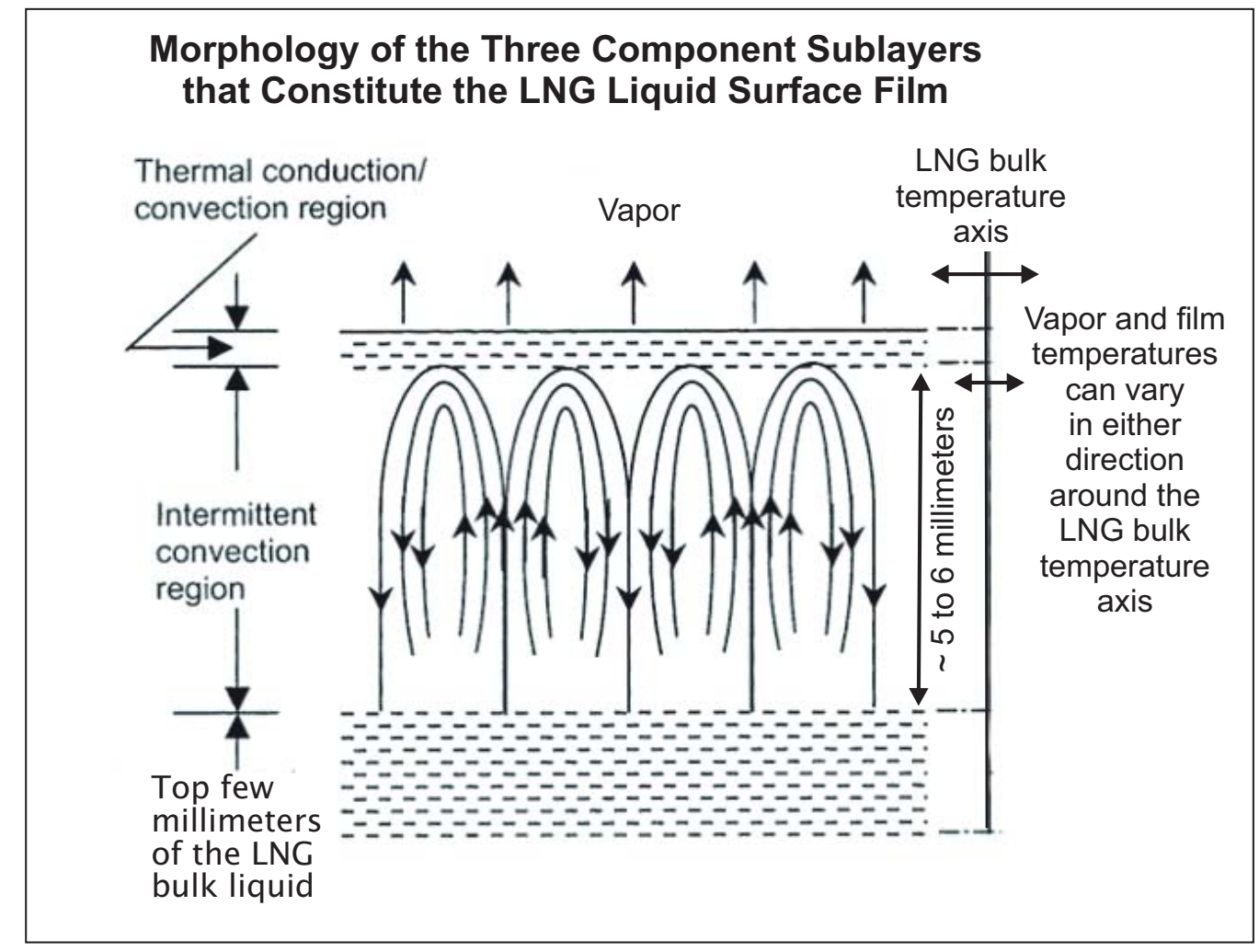

Fig. 3. Morphology of LNG surface film above the LNG bulk liquid (modified after Scurlock, 2016). 
currents throughout the LNG bulk (Scurlock, 2016) (Fig. 3). The magnitude of heat flow in this LNG sub-layer can vary from 0.1 to $1.0{ }^{\circ} \mathrm{C}$. GIIGNL (2012) estimate this at about $0.5{ }^{\circ} \mathrm{C}$ for a tank certified with a boil-off rate (BOR) of 0.15 $\% /$ day. Speed of movement of the thermal boundary sub-layer for liquid nitrogen (Paine et al., 2014) is about 1 meter/minute, for LNG it is expected to be similar.

The LNG surface film or the Hashemi-Wesson layer (Hashemi and Wesson, 1971; Paine et al., 2014) is always in thermodynamic equilibrium with tank pressure (Bates and Morrison, 1997). It has a complex structure with a vertical height estimated to be no more than 5 millimetres (Deshpande et al., 2011). Heat and mass exchange takes place between vapor and liquid across this boundary and between the film and slow convection currents within the LNG bulk. These are typically estimated using empirical correlations (Globe and Dropkin, 1959) or simulations (Baudouy, 2015; Zakaria et al., 2017). The process by which this evaporation occurs is considered to involve mass becoming part of the surface film, transitioning within it and ultimately evaporating through molecular surface film (Laciak, 2015).

In this study, we evaluate the tank-pressure tendencies of FSRU during STS transfers and highlight different circumstances that can arise influencing tank pressures during STS transfers. Rule-of-thumb equations are presented for estimating tank-pressure increases during various STS transfer conditions. These are based on the real-time observation, monitoring and careful analysis of more than 30 STS transfers on FSRU under a range of prevailing tank pressure conditions. Our objective is to improve knowledge regarding FSRU tankpressure risks and outcomes and to suggest ways in which unnecessary cargo consumption in the GCU/SD can be minimized during STS transfer operations.

\section{Method}

The method adopted is to present and describe many empirical observations of FSRU LNG tank conditions during a wide range of operational activities. The tank conditions are recorded by monitoring the tank pressure and temperature trends of the liquid and vapor phases present for various dynamic tank-fill situations. This information is used to describe and explain the non-linear observed evolving pressure and temperature trends in terms of the phases present in such tanks as operations unfold. In particular, the key roles of the surface film and the saturated vapor pressure (SVP) of the LNG in determining tank pressure trends, are explored and evaluated. The information presented comes particularly from a large number of STS transfers of LNG from LNGC to FSRU under varying prevailing operating conditions.

\subsection{LNG's surface film in containment tanks and its impact on tank pressure}

This surface film possesses some key properties that effect tank pressure:

1) The film always strives to be in dynamic equilibrium with actual tank pressure (Deshpande, 2011) and rapidly responds to pressure changes. Consequently, tank pressure may also change rapidly compared to the SVP of LNG bulk. Crucially, the LNG liquid film is in equilibrium with tank pressure, but not the whole LNG bulk. It adjusts very quickly to new SVP conditions reaching equilibrium after any pressure change, typically within about thirty minutes. On the other hand, this film and actual tank pressure are interrelated (i.e., dependent on one another); changes to one impact the other. If external activities lead to changes in tank pressure, then the film's SVP adapts to them. Also, if the LNG bulk changes its heat content then tank pressure adapts to change of temperature through the conduit of the LNG film.

2) When tank pressure equals the SVP of the LNG bulk, the film has the same SVP and temperature and is in equilibrium with the prevailing tank pressure. This is most likely to occur when the tank is nearly full and when all usage and movement is halted (i.e., no BOG removal and no LNG transfers); this stable state can then persist for some time. However, such ideal conditions rarely persist for long as routine operations lead to dynamic changes.

3) It acts as buffer zone between LNG bulk and the vapor space. It regulates mass exchange through evaporation and condensation of vapor. It operates as a "constraint" or porous medium in both directions enabling mass exchange with different effects:

a) Overpressure. When tank pressure, for whatever reason, becomes higher than the SVP of the LNG bulk, condensation prevails over evaporation (Kim et al., 2008). Excess pressure encourages vapor molecules back into the liquid state through film's surface. The resulting latent heat of condensation then warms the film, causing its SVP to rise following the increasing pressure of vapor space. At a certain moment excess pressure ceases, as the SVP of the liquid film equals the actual tank pressure and condensation excess ceases. A new vapor-liquid equilibrium is established at the surface film. The mass of the film is small allowing it to warm up (above the temperature of the LNG bulk) slowing down effective mass exchange between LNG bulk and film. This leads to the tank vapor space being compressed and pressure increasing almost linearly in practice. The warmed film acts broadly as a "blanket" that prevents large mass of vapor absorption back into LNG liquid. In such conditions the heat from LNG bulk is not released, as no excess evaporation can occur through the film. Thus, the LNG bulk absorbs all heat ingress (from tanks walls) and its bulk temperature slowly rises (Kulitsa and Wood, 2018b). Nevertheless, actual tank pressure has a greater and more rapid influence on the film than vice versa. Typically, this state is associated with high-rate STS transfers or when the low-duty compressor recycles hot vapors back into tank (at low regasification rates). The tank's vapor space decreases rapidly and BOG removal from the tank doesn't compensate sufficiently for this piston-like effect.

b) Underpressure. When tank pressure falls below SVP of the LNG bulk, for whatever reason, then the film acts as a "mesh" that delays, but does not halt, evaporation 
velocity (which in such conditions prevails over condensation). The LNG film is rapidly cooled by latent heat of vaporisation as heat is taken away by emitting vapor molecules. This process lowers the LNG film's SVP and tank pressure lowers to be in equilibrium with the film. However, mass and heat exchange between LNG bulk and film is enhanced as soon as tank pressure falls below LNG bulk SVP. This is because the film is colder than the LNG bulk and situated above it. Evaporation rate increases the more tank pressure tends to fall below the LNG bulk SVP. The LNG bulk effectively resists tank pressure falling significantly below the LNG bulk's SVP. Tank pressure is thereby inhibited from falling significantly below the LNG bulk's SVP. It becomes held dynamically steady at certain pressure level below the SVP of LNG bulk. That dynamically floating pressure below LNG bulk SVP is governed by the amount of BOG removed from tank. Increasing BOG removal significantly enhances evaporation from the film (i.e., by orders of magnitude). However, the further dynamic lowering of tank pressure such BOG removal causes is only minor. Establishing a steady state takes up to about one hour after any change in BOG. Empirical observations on FSRU indicate that actual tank pressure may be dynamically held floating below the SVP of LNG bulk by about 10 to 50 mbars at boil-off evacuation rates of 2 to 12 ton/hour, respectively. These values apply to a typical FSRU with four tanks (i.e., 150,000 to $170,000 \mathrm{~m}^{3}$ tanks with $0.15 \%$ /day NBOR rating).

In such conditions, the LNG bulk is releasing heat because evaporation is prevailing. However, the LNG bulk itself may cool down or warm up, depending on whether heat lost via evaporation or heat ingress into LNG bulk dominates. Tank pressure tends to follow the prevailing condition of the film to reach equilibrium. This state is typical of FSRU tanks during regasification operations that are not being impacted by high-rate STS transfer operations.

4) Liquid film can be easily destroyed mechanically, by sloshing or during rollover events (Rudman et al., 2009; Kulitsa and Wood, 2018b), or severely disrupted for a short period of time. The film re-establishes itself within a short period of time once the disrupting forces cease. A destroyed or disrupted film has a great impact on tank pressure as the LNG bulk mass then exists with no constraining layer (surface film) between it and the vapor space. This results in the following related effects:

a) Film broken when tank pressure is higher than the LNG bulk SVP: Liquid at the surface tends to reach an equilibrium state with tank pressure. This drastically enhances condensation due to the subcooled state of the LNG on surface. Consequently, tank pressure declines as some vapor mass is absorbed into the LNG via condensation. Enhanced condensation rates continue until a film is self-restored and reaches equilibrium with reduced tank pressure. If the film is disrupted for long enough tank pressure equilibrates with the LNG bulk's SVP. b) Film broken when tank pressure is lower than the LNG bulk SVP: Liquid at surface tends to reach an equilibrium state with tank pressure. This drastically enhances evaporation causing tank pressure to rise rapidly due to the vapor mass emitted casued by the superheated state of the LNG at the surface. Tank pressure rises rapidly to match the SVP of LNG bulk. Enhanced evaporation rates continue until a film is self-restored, re-establishing its mesh effect. This is the case with rollover events, i.e., evaporation rate and tank pressure increase very rapidly (Arjomandnia et al., 2013; Ludwig et al., 2013). Again, if the film is disrupted for long enough tank pressure equilibrates with the LNG bulk's SVP.

The LNG surface film is relatively easily disrupted, e.g., by agitation during tank top filling. Sloshing in tanks when LNGC are sailing in relatively slight to moderate seas (Chen et al., 2009; Grotle and Esoy, 2018) will also destroy the surface film (in situation 4b) leading to a rise in tank pressure (Kulitsa and Wood, 2017b; Wood and Kulitsa, 2018). Once the sea calms the tank pressure typically returns rapidly to its original value as the surface film re-forms. Such disruption also explains some of the sagged tank-pressure trends observed in some STS transfers where vapor space is compressed, condensation rate of vapor is slightly enhanced due to disruptions of the film and overpressure (i.e., situation 4a).

Note, the term "sag" is used here to mean not only an absolute decline in pressure but also a non-linear upward pressure trend with a convex-downwards shape.

The impacts of the LNG film on tank pressure, and vice versa, are dynamic (Kulitsa and Wood, 2019). They remain effective as long as external processes persist but, once they cease the system rapidly returns to a static state (tank pressure equilibrates with SVP of the LNG bulk). Equilibrium conditions exists just near the LNG surface. Vapor some distance above the LNG surface will be gradually heated up by heat ingress and volumetrically expand. This effect slowly increases tank pressure above the LNG bulk's SVP. Eventually, this leads to an overpressure condition with LNG film responding as described to such a condition. That process develops slower than that associated with situation $3 \mathrm{a}$.

Due to the large size of LNG storage in typical LNG storage tanks, the process occurs in practice in a more complex way than described as a basic physical concept, as it exists dynamically with various transition states and stable points. The three components (LNG bulk, surface film and vapor space) constantly interact with one another dynamically. The film and vapor space rapidly influence one another and settle in equilibrium after a short transition state whenever any changes occur to tank processes (e.g., increase in BOG offtake, reduced STS transfer rates, etc.). The LNG bulk also influences the film-vapor phase relationship. Consequently, the actual tank pressure generally does not match the SVP of the LNG bulk at any specific moment as these processes are ongoing. The SVP of the LNG bulk acts as a demarcation line that defines two distinct operational states of vapor-liquid system behavior that 


\section{Diagrammatic Representation of Pressure Duality Behavior in FSRU Tanks}

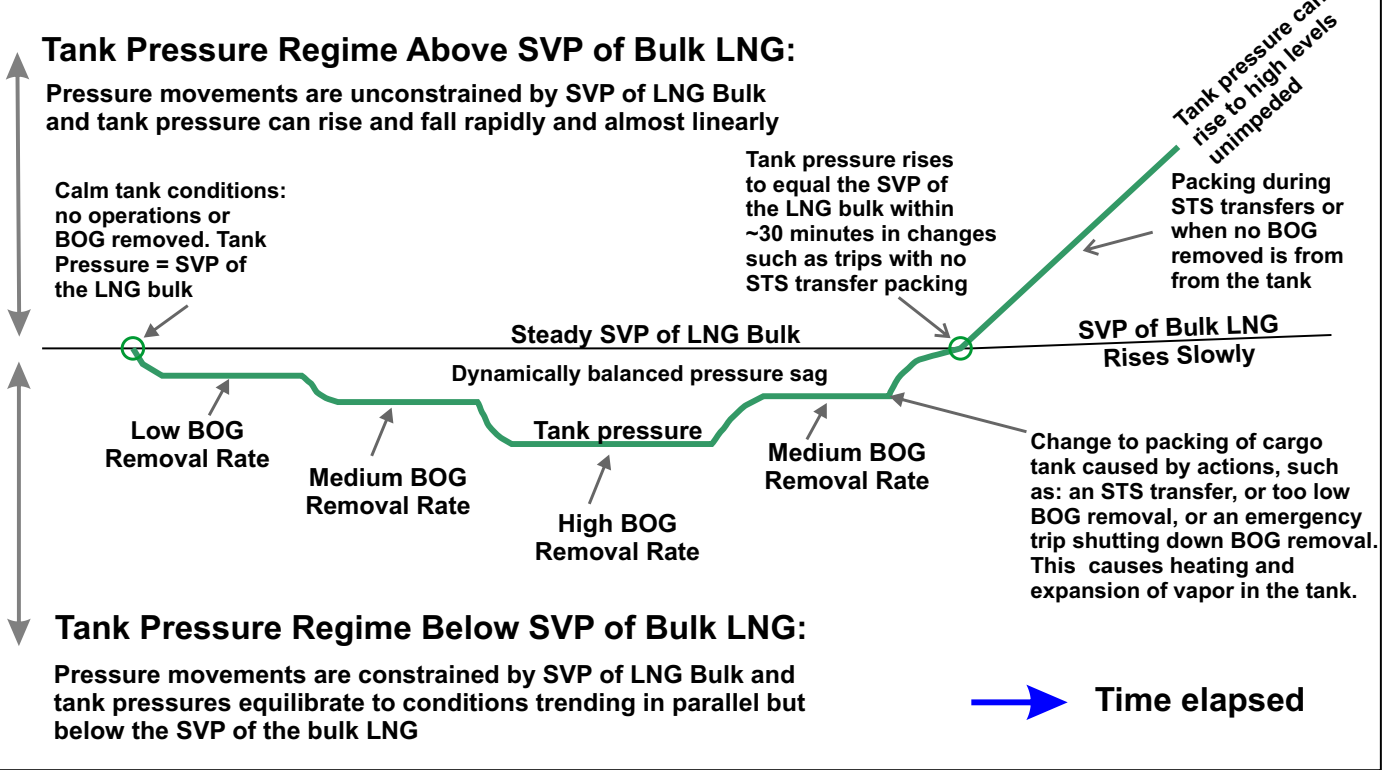

Fig. 4. Schematic summary of pressure duality in tanks depending on BOG evacuation rate, compression state and with reference to the SVP demarcation line.

typically persist in the LNG storage space. A third state occurs occasionally, i.e., when actual tank pressure equals the SVP of the LNG bulk. That equilibrium state between the film and vapor space, just above the LNG surface, in practice appears as transient condition. It occurs just briefly, between the other two practically persistent, and in detail dynamic, continuously adjusting states. This observed phenomenon, referred to as duality in tank pressure behaviour (Fig. 4), is explored here in detail. A numerical case showing the impacts of duality on tank pressure trends is described in Appendix A.

\subsection{Practical significance of tank pressure duality}

There are practical applications of duality in the behaviour of tank pressure for tanks containing LNG. Typically, operators tend to lower tank pressure by increasing BOG removal rates (in GCU or SD) during STS transfers. Such actions take no account of tank pressure being inhibited from descending significantly below LNG bulk's SVP, irrespective of the magnitude of BOG removal. Thus, at specific moments it appears that whatever BOG quantities are evacuated from the tank, tank pressure remains broadly stable and does not broadly reduce further. Such actions lead to large cargo loss with negligible benefits in terms of lowering tank pressure. Burning gas in the GCU or SD before an STS transfer as a preventative action in attempts to pre-empt tank pressure increase in such conditions is a futile, unnecessary and wasteful action as just controlling pressure during an STS transfer is more effective (Kulitsa and Wood, 2017a, 2017b; Wood and Kulitsa, 2018). Understanding tank pressure duality behaviour helps to make appropriate and meaningful commercial decisions regarding effective tank pressure control. Such understanding also helps to forecast likely tank pressure trends during STS transfers depending on expected conditions. This leads to more rational decisions regarding when it is necessary to burn BOG in the GCU or SD when it is appropriate and avoid significant waste of cargo. This helps to prevent overconsumption in GCU/SD beyond that required for safety requirements. On the other hand, awareness that tank pressures are able to increase rapidly to levels significantly above the SVP of the LNG bulk with a near-linear tendency, makes pressure trends easier to predict and control.

\section{Results}

\subsection{Dynamic balance of component volumes in an LNG tank}

The normal boil-off gas rate (NBOR) is a certified (by the tank manufacturer) heat-leakage rate into LNG tanks via their insulation. NBOR is typically about $0.15 \%$ of full cargo capacity per day for today's FSRU. This metric determines the mass of BOG to be evaporated and removed from the LNGliquid surface to counteract natural heat ingress into the tank and to maintain tank pressure stable. When the total mass of the vapor (heat of evaporation) removed from a tank is less than its NBOR value (natural heat ingress) and induced heat in the tank (i.e., from in-tank pumps, recirculation actions, etc.), part of that heat is accumulated in the LNG liquid bulk. This causes the LNG's temperature to rise, and thereby increases the SVP of the LNG bulk, leading eventually to an increase in tank pressure. On the other hand, if the mass of BOG removed from an LNG tank is above that necessary to compensate for natural and induced heat ingress then the LNG bulk liquid is 

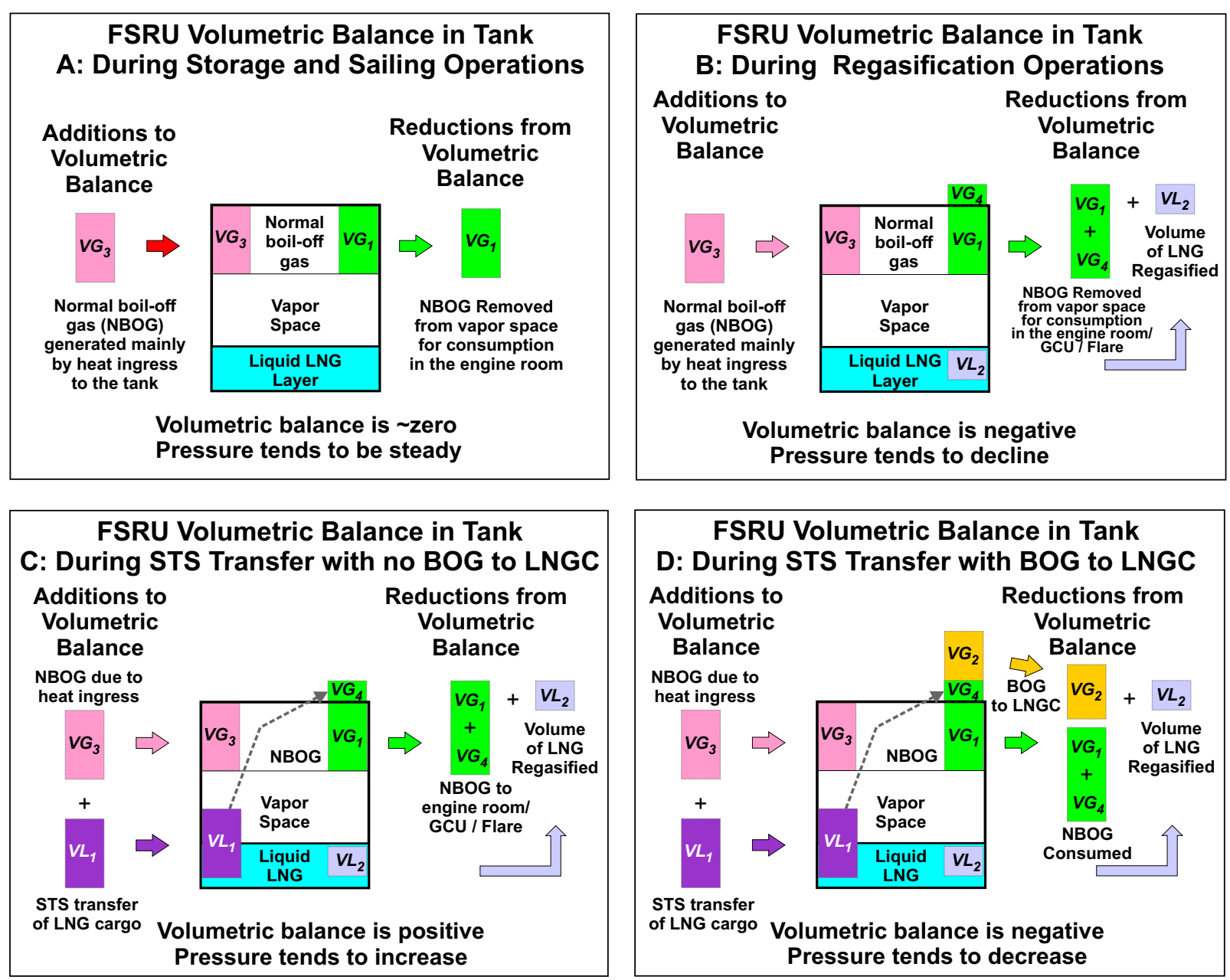

Fig. 5. Diagrammatic representation of different volumetric balances that typically occur in FSRU tanks.

cooled, and its SVP is reduced, leading, eventually, to actual tank pressure being reduced. In both cases, tank pressure equilibrates dynamically with the film. The film's SVP is held floating just below the momentary SVP of the LNG bulk and evolves parallel to the SVP changes of the LNG bulk (Section 2 Case 3b). Consequently, tank pressure is also maintained lower than the SVP of the LNG bulk, even if the LNG bulk is slowly warming and tank pressure slowly rises.

This fundamental tank-pressure behaviour, and resulting trends in-tank pressure, need to be kept in mind when considering the impacts of STS transfers into FSRU tanks pressure. During various routine operations associated with FSRU there are methods to estimate tank pressure and forecast characteristic pressure trends that consider the fundamental behaviour of LNG in tanks and take into account all the factors that affect tank pressure. We refer to this tank pressure assessment as volumetric balance, which is the sum of all volumes moving into and out of a tank over a specified period of time.

During an STS transfer to an FSRU tank the components of the volumetric balance are quite complex and dynamic. From experience, STS transfer rates below 3,000 to 4,000 $\mathrm{m}^{3} / \mathrm{h}$ are usually conducted "within" modern FSRU BOG handling capacity and without vapor return. This means that no compression of the tank vapor space occurs in such conditions and FSRU tank pressures remains dynamically floating below SVP of LNG bulk. However, transfer rates on LNG typically are conducted at 6,000 to $10,000 \mathrm{~m}^{3} / \mathrm{h}$ and, consequently, vapor-space compression is inevitable. On the other hand, the ongoing and varying operations of the FSRU's BOG handling equipment (e.g., engine-room fuel feed, recondenser, STS vapour return, GCU, flaring/venting, etc.) removes some mass of vapor from the tank's vapor space, that is equivalent to a specific volume at the prevailing tank conditions (i.e., pressure and temperature of the tank's vapour phase). Most land-based LNG receiving terminal and many modern FSRU are equipped with recondensers and they play a key role in their operations (Li et al., 2012; Hayashi et al., 2016). The STS transfer continues, progressively adding new volumes of liquid into the FSRU tank, but regasification feed (for gas send out) also, continuously removes some volumes of liquid from the LNG tank.

The sum of all these actions establishes a difference or balance $(\Delta)$ between the volumes removed from the FSRU tank and the volumes pumped into the tank. Depending on the volumes associated with each action a positive, negative 


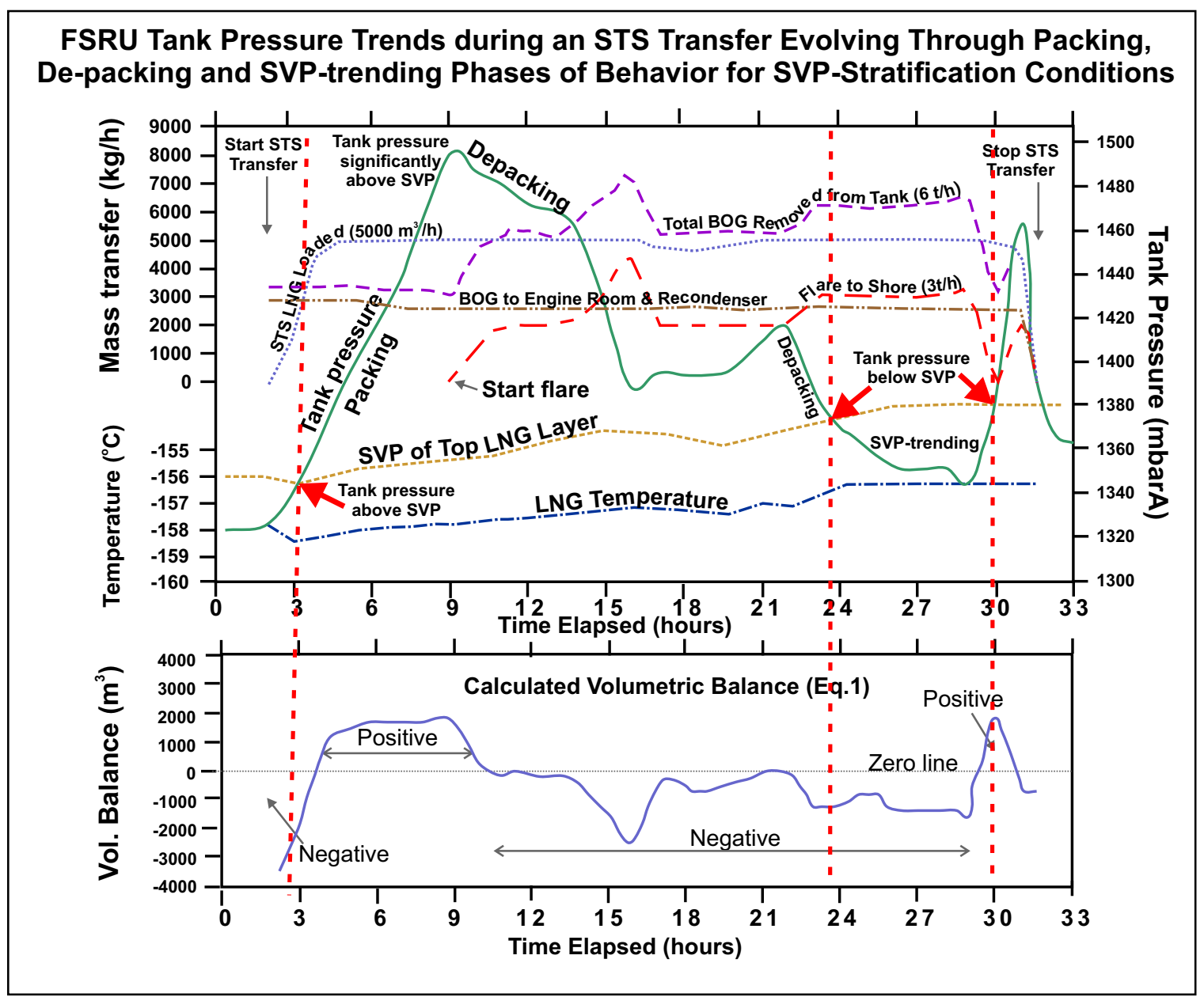

Fig. 6. Real STS without BOG return to shore or to LNG. Change of volumetric balance and reaction of tank pressure. The entire range of pressure-duality behaviour is depicted.

or zero $\Delta$ results. That $\Delta$ to the volumetric balance determines the changing FSRU tank pressure trend. Tank pressure may either rise or fall almost linearly or settle dynamically just below the SVP of the LNG bulk.

When the volumetric balance is positive (tank packing case), tank pressure rises, near-linearly, significantly above the SVP of the LNG bulk (Section 2 Case 3a). When the BOG volume removed exceeds the volumes being pumped into the FSRU tank the volumetric balance is negative (depacking case) leading to an SVP-trending outcome after the LNG bulk's SVP is reached. (Section 2 Case $3 b$ ).

Eq. (1) expresses the momentary volumetric balance (ignoring temperature or composition differences):

$$
\Delta_{s t s}=V L_{1}-V L_{2}-V G_{1}-V G_{2}+V G_{3}-V G_{4}
$$

where $\Delta_{s t s}$ is volumetric balance in cubic metres $\left(\mathrm{m}^{3}\right)$ for an FSRU tank following an STS transfer; $V L_{1}$ is the volume $\left(\mathrm{m}^{3}\right)$ of LNG liquid loaded into the tank during the STS transfer; $V L_{2}$ is the volume $\left(\mathrm{m}^{3}\right)$ of LNG liquid extracted from the tank and regasified; $V G_{1}$ is the volume $\left(\mathrm{m}^{3}\right.$ at tank condition) of boil-off gas (BOG) removed from the tank during the STS transfer and sent to the engine room and the FSRU recondenser; $V G_{2}$ is the volume ( $\mathrm{m}^{3}$ at tank condition) of BOG from the FSRU tank returned to the LNGC during the STS transfer, if a vapor return line is available; $V G_{3}$ is the volume $\left(\mathrm{m}^{3}\right.$ at tank condition) of BOG generated in the FSRU tank due to heat ingress (i.e., NBOR process) plus heat induced by running the in-tank pumps; and $V G_{4}$ is the volume $\left(\mathrm{m}^{3}\right.$ at tank condition) of BOG removed from the FSRU for BOG extra control purposes (i.e., running the gas consumption unit (GCU) or extra gas burned running the steam dump (SD) or sending the gas to a flare onshore). We distinguish this component of BOG in this article and refer to it as loss of cargo.

Fig. 5 illustrates volume balances for four distinct situations that may occur in FSRU.

Over the time taken to complete an STS transfer the volumetric balance is variable and may change sign, perhaps several times, depending upon the relative ongoing contributions of each Eq. (1) component.

Fig. 6 illustrates the FSRU tank-volume changes (in and out) and defines tank pressure conditions during real STS transfers based on hourly information (i.e., pressure and temperature trends are actual recorded measurements and other values are calculated). The demarcation line used for differentiating the transition of tank pressure behaviour between the 


\section{FSRU Tank Pressure Trends during an STS Transfer Evolving Through Packing, De-packing and SVP-trending Phases of Behavior for SVP-mix Conditions}

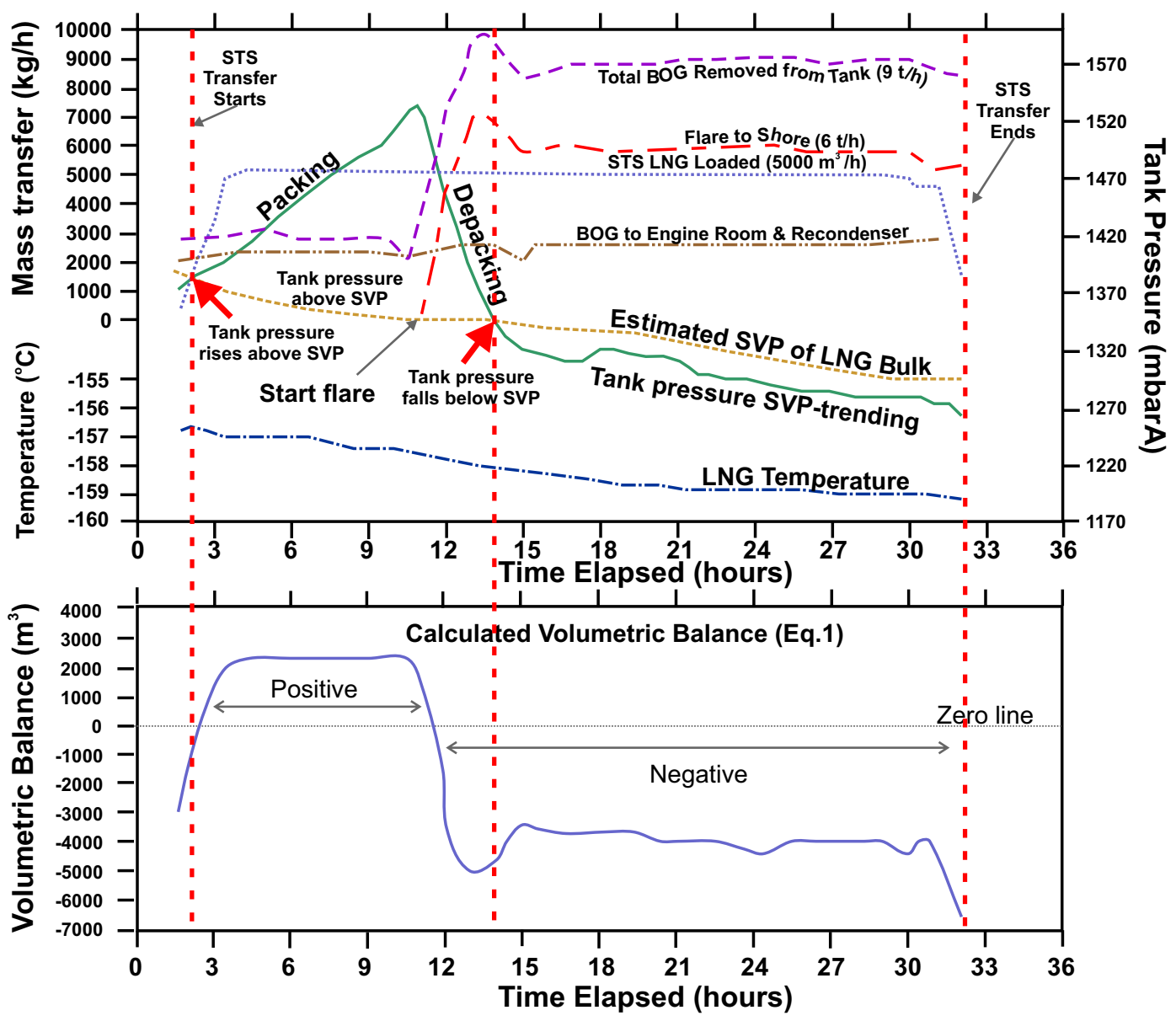

Fig. 7. Real STS without BOG return to shore or to LNGC. Change of volumetric balance and reaction of tank pressure. The entire range of pressure-duality behaviour is depicted.

two states of the dual-pressure-response model described is the SVP of the LNG bulk. Momentary volumetric balance and its trends (i.e., negative, positive or zero) distinguishes the state and change tendency in the tank's prevailing pressure (rising, falling or steady). Unfortunately, the volumetric balance may not always provide the correct pressure trend calculation. This is because when tank pressure is at or below the SVP of the bulk LNG tank pressure is not governed by a linear process related to compression. It is only accurate when tank pressure is at or above the SVP of LNG bulk (i.e., in the overpressure range). However, it can provide insight to the likely forward-looking tank-pressure trend. For tank pressures above the SVP of the LNG bulk (i.e., the condition represented illustrated in Fig. 7) the ongoing change in tank pressure follows a near-linear trend either upwards (packing) or downwards (depacking). Once tank pressure reaches the SVP of the bulk LNG, then tank pressure dynamically floats at a pressure just below that SVP, defined by the prevailing mass of evaporation.
Eq. (1) does not account for tank pressure change related to SVP change caused by compositional (specifically methane content) or temperature changes to the LNG in the tank. This can lead to situations when the volumetric balance is negative, but the tank pressure may continue to rise (not linearly and only up to a certain level). This would occur due to an increase in SVP of the bulk LNG as a leaner, lighter LNG is introduced into a richer, heavier cargo during an STS transfer. This causes tank pressure to rise even though it remains below the SVP of the LNG bulk and large BOG disposal is occurring (i.e., despite a large negative balance throughout). When the LNG bulk temperature changes as newly-introduced LNG enters the tank, the SVP of the LNG bulk changes (when there is no stratification) leading to tank pressure changes, while the tank pressure continuously floats below the SVP of the LNG bulk. Here tank pressure follows the compositional and temperature driven changes of LNG bulk SVP.

If the tank pressure remains above the SVP of the LNG bulk (especially by some margin) then the changes to the 
Table 1. LNG density and LNG bulk SVP relationships at a constant temperature for LNG of different compositions encountered in commercial trade typically handled by FSRU.

\begin{tabular}{|c|c|c|c|c|c|}
\hline \multicolumn{6}{|c|}{ SVP and LNG Characteristics for a Range of Commercially Traded LNG Cargoes Frequently Delivered to FSRU } \\
\hline $\begin{array}{l}\text { LNG Cargo } \\
\text { Reference } \\
\text { Number }\end{array}$ & LNG Cargo Source & $\begin{array}{l}\text { Ranked in As- } \\
\text { cending Order of } \\
\text { SVP (mbarA) }\end{array}$ & $\begin{array}{l}\text { Methane Content } \\
\text { of LNG (\% mol) }\end{array}$ & $\begin{array}{l}\text { LNG Density } \\
\left(\mathrm{kg} / \mathrm{m}^{3}\right)\end{array}$ & $\begin{array}{l}\text { Pressure Differ- } \\
\text { ence Relative to } \\
\text { Cargo \#1 }\end{array}$ \\
\hline 1 & Ras Laffan Qatar (aged) & 1154 & 92.8 & 445.0 & 0 \\
\hline 2 & Bonny Nigeria & 1155 & 90.8 & 451.7 & 1 \\
\hline 3 & Hammerfest, Norway & 1160 & 91.8 & 447.5 & 6 \\
\hline 3 & Ras Laffan Qatar (recently loaded) & 1161 & 93.7 & 437.6 & 7 \\
\hline 5 & Commingled LNG (more than one source) & 1190 & 95.5 & 434.3 & 36 \\
\hline 6 & Commingled Atlantic Trinidad (aged) & 1196 & 96.2 & 431.0 & 42 \\
\hline 7 & Atlantic Trinidad (aged) & 1207 & 97.5 & 427.7 & 53 \\
\hline 8 & Zeebruge Belgium (reloaded) & 1210 & 91.3 & 439.0 & 56 \\
\hline 9 & Commingled Ras Laffan Qatar (aged) & 1212 & 93.5 & 438.1 & 58 \\
\hline 10 & Atlantic Trinidad (newly loaded) & 1215 & 97.7 & 426.4 & 61 \\
\hline 11 & NWS Australia (aged) & 1246 & 98.7 & 423.4 & 92 \\
\hline
\end{tabular}

Data for all samples is measured at a reference temperature of $-159{ }^{\circ} \mathrm{C}$.

At another reference temperature the relative distribution of the sample values would be the same as that shown.

SVP of the LNG bulk (combined composition and temperature changes) are effectively obscured by the overpressure. If tank pressure floats dynamically balanced below the SVP of LNG bulk (i.e., with any negative volumetric balance), then it will inevitably follow synchronously the SVP changes of the LNG bulk.

Table 1 provides the composition, density and SVP ranges (at a constant temperature, $-159.0^{\circ} \mathrm{C}$ ) of LNG from different sources impacted by LNGC marine transport and STS transfer mixtures. This range of LNG states could be encountered by operating FSRU during an STS transfer. For instance, the heel cargo in the FSRU could be of a composition \#1 (Table 1) and the LNG pumped into that tank could be of composition \#11, or vice versa. Those two LNG parcels display an extreme SVP difference of $\sim 90$ mbar. In the case where composition \#1 (high-density) is pumped into a tank holding LNG of composition \#11 (low-density) stratification would ensue (Kulitsa and Wood, 2017b, 2018b). Tank pressure is then governed exclusively by the old cargo heel (top layer with composition \#11), whereas the new cargo does not affect tank pressure until a rollover occurs. However, in the case where composition \#11 (low-density) is pumped into a tank holding LNG of composition \#1 (high-density), the in-tank LNG gradually commingles and the SVP of the LNG bulk increases proportionally towards that of the incoming light LNG. This will cause tank pressure to inevitably rise by up to about 90 mbar, even in the STS-SVP-trending case (Fig. 9b).

\subsection{Types of STS transfers based on volumetric balances and cargo qualities}

Common STS transfer patterns can be distinguished based upon their pressure change tendencies and outcomes. Factors that need to be taken into consideration are: Whether strati- fication or complete mixing of the cargo prevail; volumetric balance (VB) value and it progression during the course of the STS transfer; whether tank pressure is likely to cross the demarcation line described and become an SVP-trending case; value of the LNG bulk's SVP; and its temperature and compositional changes during STS transfer.

Fig. 8 distinguishes four types of STS transfer patterns using such an approach. The SVP of the LNG bulk is critical as it represents a demarcation line between the "SVP trending" and "packing" cases. There is no static STS transfer outcome, LNG in the FSRU will either become stratified or mixed. Depending on the operational conditions and operator's responses to those conditions, the SVP demarcation line may be "crossed", at which point "packing" conditions would change to "SVP trending" conditions, or vice versa.

STS Mix + SVP-trending Case 1 (Figs. 9a and 9b) This involves transfers of light LNG cargo injected into a heavy heel cargo, while a negative volumetric balance is maintained. STS transfer occurs at medium rates with vapor return to LNGC. The LNGC cargo being transferred is less dense than the LNG heel and complete broadly immediate mixing results in a new LNG bulk quality and temperature. The LNG's mixed quality slowly evolves during the first $50 \%$ of the STS transfer until a broadly stable LNG quality (i.e., SVP and temperature), close to the overall LNGC cargo quality, prevails. In this case, tank pressure throughout the STS remains dynamically held floating just below the SVP of the evolving newly mixed LNG bulk. On this basis, it is possible to predict typical pressure curves during such STS transfers and to determine a reliable maximum expected tank pressure.

The volumetric balances for such cases are negative and cannot be used for direct pressure calculations.

STS Mix + Packing Case 2 (Figs. 11 and 12) The STS transfer occurs as per case 1, except that tank pressure is 


\section{Volumetric Balance Outcomes for STS Cargo Transfers to FSRU for Different Prevailing Tank Conditions}
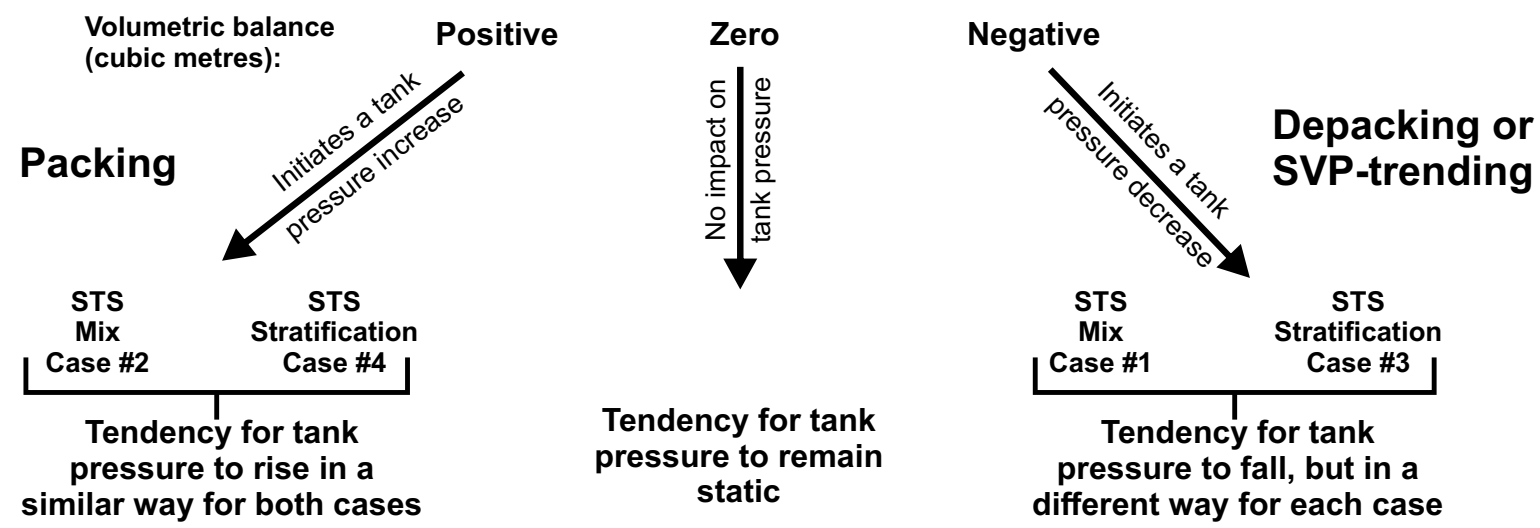

Fig. 8. Types of STS transfer to FSRU determined by mixed or stratified outcomes in prevailing FSRU packing and depacking tank operating conditions (see text for detailed description of these four cases).

maintained above the SVP of the evolving new LNG bulk throughout. The volumetric balances for this case are positive, because vapor removed from the tank is too low to prevent the tank's vapor space from being physically compressed (i.e., packed). Tank pressure may vary significantly upwards (packing) and downwards (de-packing) following broadly linear trends (as typically actual tank pressure remains above LNG bulk's SVP) depending upon the operating actions instigated on-board the FSRU. When tank pressure is above the LNG bulk's SVP and the volumetric balance changes to negative due to some changes in operational conditions, the tank pressure will fall almost linearly towards the SVP of the LNG bulk. Once that SVP is reached the case then becomes the STS-mix plus SVP-trending.

Observations reveal that following a near-linear rise in tank pressure trend that displays a slight non-linear sag. This reflects the effect of the surface film being significantly breached by upwelling liquid LNG and enhanced/excess condensation on the LNG surface taking place. In such conditions, a much more significant mass of vapor is condensed, particularly during the initial third of the STS transfer when the tank LNG level remains relatively low (for effective film disturbances). Volumetric balance can be used for close estimation of tank pressure (the average tank pressure line is depicted as a linear trend).

STS Stratification + SVP-trending Case 3 (Fig. 10) Throughout the STS transfer FSRU tank pressure floats dynamically below the SVP of the Top Layer LNG bulk). This means that essentially the Bottom Layer LNG plays no role in determining tank pressure until a rollover occurs (Kulitsa and Wood, 2018a, 2018b). The new LNG cargo pumped into the FSRU tank, whatever its composition or temperature, is effectively "sealed off" from having any effect on FSRU tank pressure during the STS transfer and for as long as stable stratification remains. The magnitude of the SVP of the toplayer LNG bulk is determined solely by the relatively small mass of this layer (formerly the LNG heel). The typical FSRU tank pressure trend for this type of STS transfer is lower (than Case 1) and stabilizes at about 20\%-30\% of the STS transfer is completed. Due to the relatively small mass of the LNG heel, cooling of this relatively small top-layer LNG is highly efficient. It is achieved by typical boil-off extraction rates (unlike Case 1 where the liquid LNG cargo whole mass needs to be cooled). This type of STS is typically characterised by lowest pressure rise observed of any STS transfers (Fig. 12). The volumetric balances for this case are negative and cannot be used for direct pressure calculations. However, its characteristic pressure curve is easy to predict, generally displaying a pressure decline tendency due to cooling effects (Fig. 10).

STS Stratification + Packing Case 4 (Fig. 11) Throughout the STS transfer the FSRU tank's vapor space is compressed (like Case 2). A key difference in this case is that the tank's vapor space is compressed and there is no tank pressure sag observed. In fact, the pressure trend is almost linear. Because the surface film is never destroyed or disturbed by newly loaded LNG, the tank pressure rise is closer to linear than for Case 2 (as condensation of LNG is minimal in this case). The newly introduced cargo is "sealed off" by TopLayer LNG from having any effect on FSRU tank pressure in the prevailing stratification. The pressure curve is similar to that associated with a tank containing just vapor with no liquid present. Typically, FSRU tank pressure rises or falls linearly and is relatively easy to predict and control. The volumetric balances for such cases are positive or negative and can be directly used for tank pressure calculations when tank pressure is above the SVP range.

When the volumetric balance becomes negative (e.g., due to higher BOG removal from the tank or at the end of an STS transfer) then tank pressure falls with a near-linear tendency until the SVP of the top-layer LNG bulk is reached, at which point "STS stratification + SVP-trending" conditions come 


\section{Schematic Tank Pressure and SVP Trends During STS Transfer to FSRU Case 1: STS-Mix with SVP-Trending Conditions Prevailing}

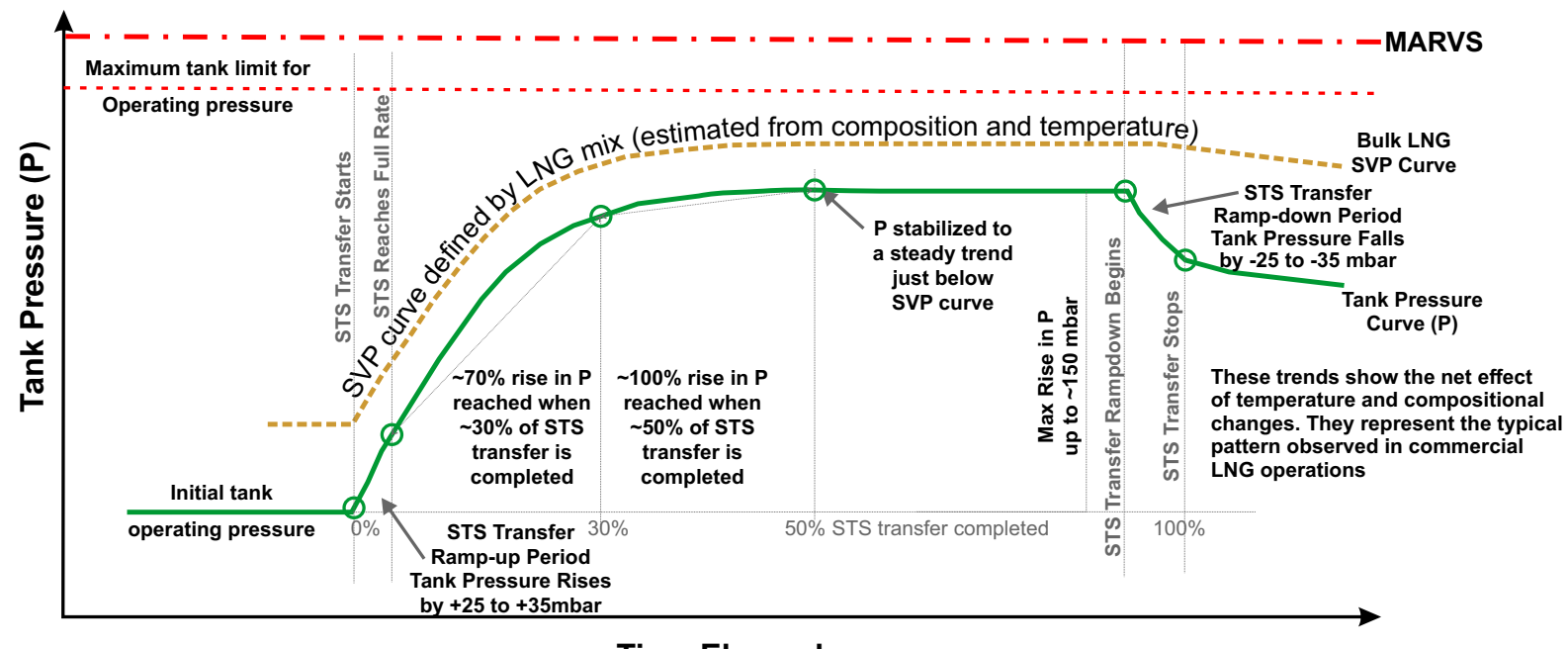

Time Elapsed

Notes: (1) The maximum worst-case scenario SVP rise (starting from before STS commences) is caused by changes in LNG composition and temperature. In practice, SVP increases of about 100 to $150 \mathrm{mbar}$ are observed for such reasons but could, in theory reach 200 mbar..

(2) In cases of SVP trending conditions, prevailing tank pressure will be held dynamically below current SVP of LNG by up to 40 - 50 mbar before and after an STS transfer 15 - 25 mbar below SVP due to rebalancing.

(a)

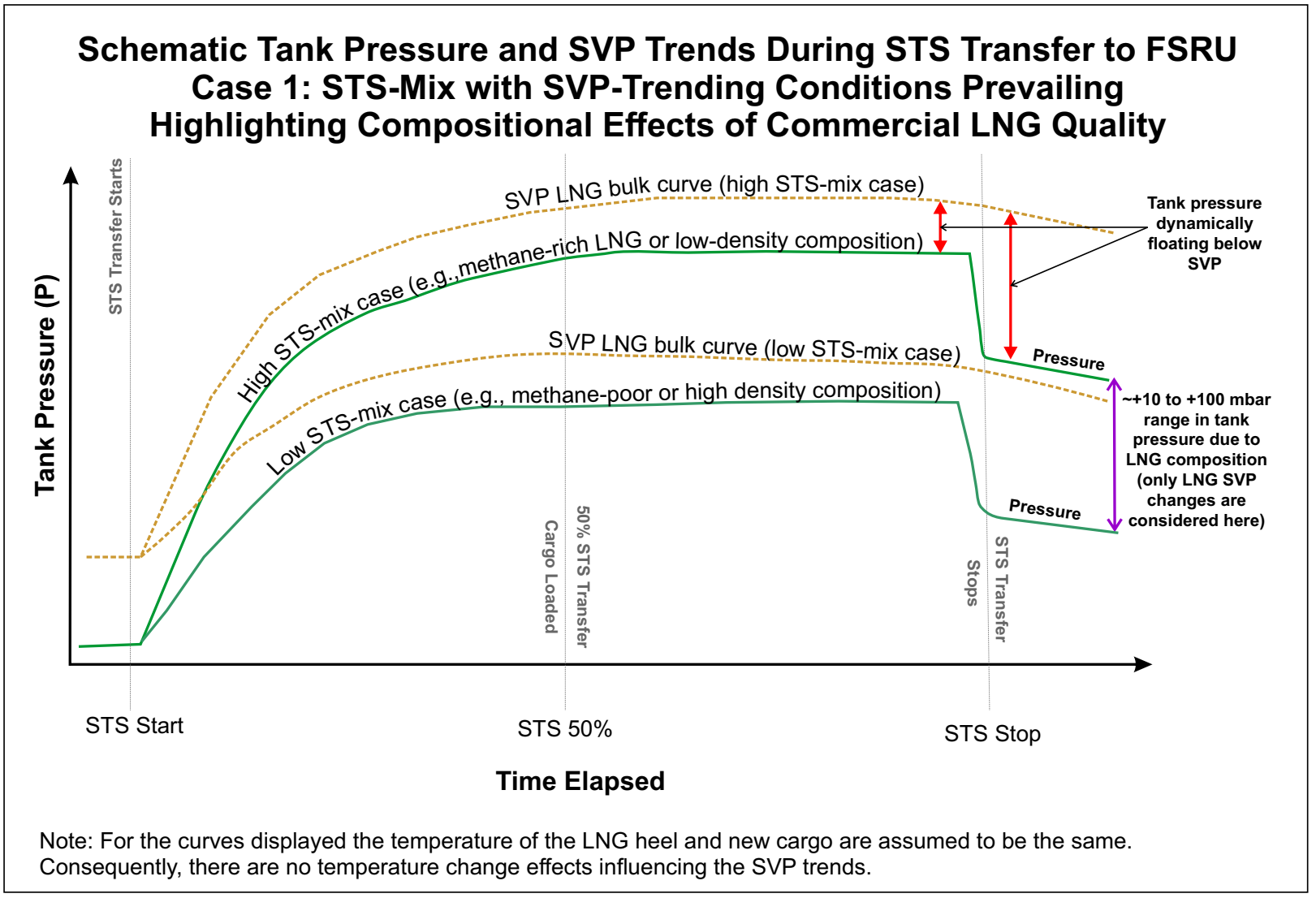

(b)

Fig. 9. (a): Characterising FSRU tank pressure and SVP of LNG bulk trends for STS Mix plus SVP-trending Case 1; (b): Effect of only compositional change to SVP of evolving LNG bulk during STS Case 1. 


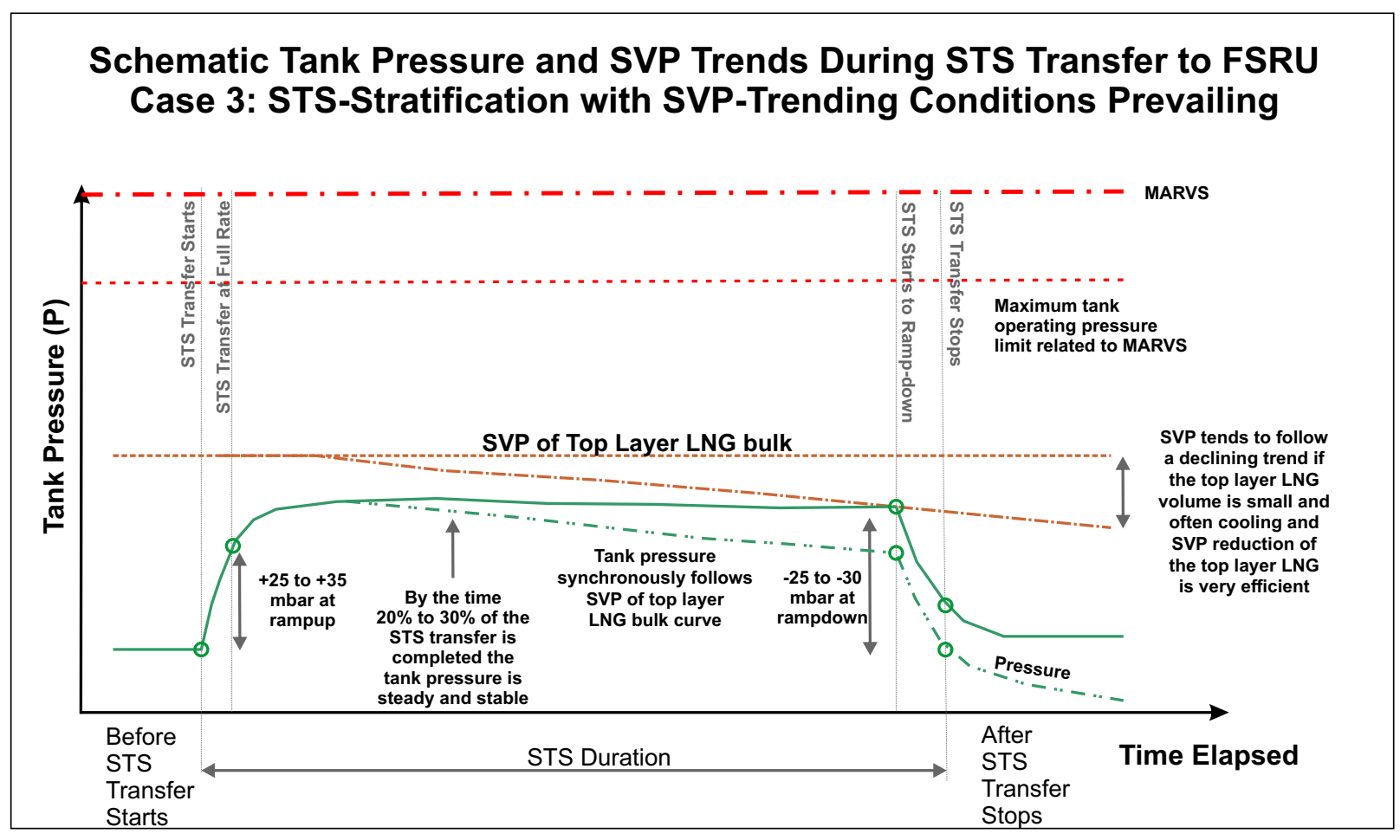

Fig. 10. Characterizing FSRU tank pressure curve for Case 3 LNG SVP trending conditions during stratification.

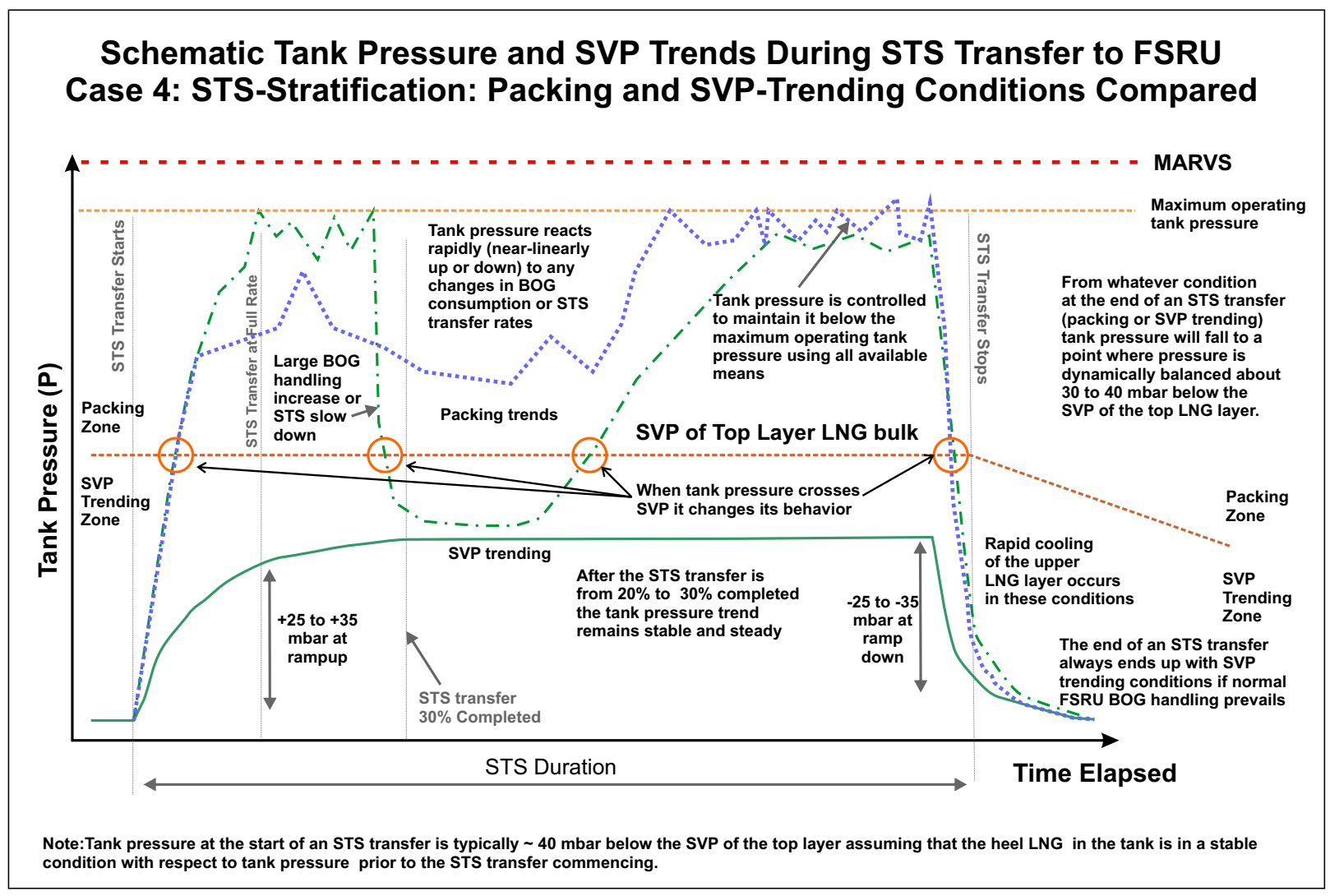

Fig. 11. Schematic FSRU tank pressure trends for STS packing versus SVP trending conditions. Also illustrated is a single STS transfer when tank pressure crosses the described SVP demarcation line, up and down, during the transfer. 


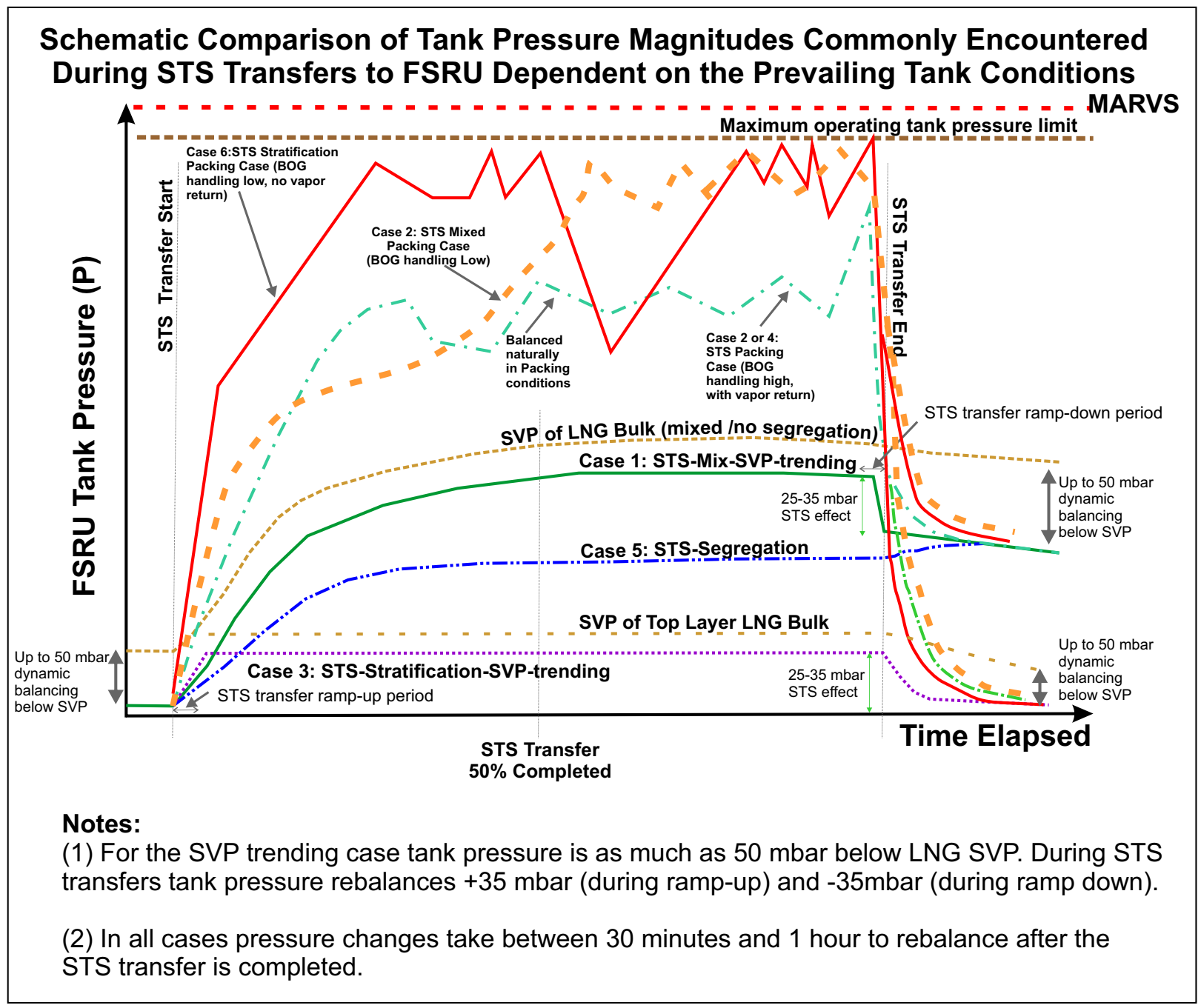

Fig. 12. Schematic magnitude comparison of all STS tank pressure curve types and SVP of LNG bulks for mix and stratification cases depending on prevailing conditions of STS transfers. See text for a detailed description of Cases 1 to 6 identified.

into effect.

STS Segregation Case 5 (Fig. 12) This scenario can occur with packing, depacking or SVP-trending tank conditions during an STS transfer. It requires some FSRU tanks hold stratified LNG and the other tanks contain only either heel or new cargo introduced during the STS transfer. This typically happen on FSRU when the delivered LNG parcel is smaller than the capacity of the FSRU. SVP-trending tank pressure (with a negative volumetric balance), similar to Case 1 , prevails. The tank pressure trend closely follows the SVP of the LNG bulk of only unstratified tanks with newly introduced cargo or old heel cargo. In such cases, the mass of the LNG influencing pressure is limited to broadly one tank. The other tanks are stratified and their top layers are typically warming up and not emitting BOG, making only minimal contributions to tank pressure. The tank controlling the pressure trend has its LNG mass cooled efficiently by boil-off extraction. This causes the LNG SVP to drift downwards. The evolving pressure trend is similar to case 1 but its magnitude lies somewhere between cases 1 and case 3 (Fig. 12). In packing conditions tank pressure trend is similar to Case 2 where, sometimes, high rates of surface condensation occur, resulting in a more significant sag in the tank pressure trend. The volumetric balances for such cases could be either negative or positive and their pressure trends are predicted as for other such cases. Generally, such a trend is harder to predict than for non-segregated cases but is always less in magnitude compared Case 1.

Any of the above STS transfer scenarios without vapor return to LNGC Case 6 (Fig. 12) This can occur with any of the described cases when much reduced BOG handling capabilities prevail in FSRU tanks. Rapid tank packing conditions result leading to very fast increases in tank pressure. Any delay or slowdown in boil-off extraction from the FSRU tanks will cause tank pressure to rise much more rapidly. This means that high gas consumption will likely be required in the FSRU's GCU or SD or, in the case of emergencies, venting to a shore mast may be necessary. Moreover, STS transfer rates above about 5000 to $6000 \mathrm{~m}^{3} / \mathrm{h}$ are not possible with the BOG handling capacity available on modern FSRU with tanks 


\section{FSRU Tank Pressure Responses Relating to Boil-off Gas Removal During STS Transfer Operations}

\section{A) STS-Packing Conditions Prevail in Tank}

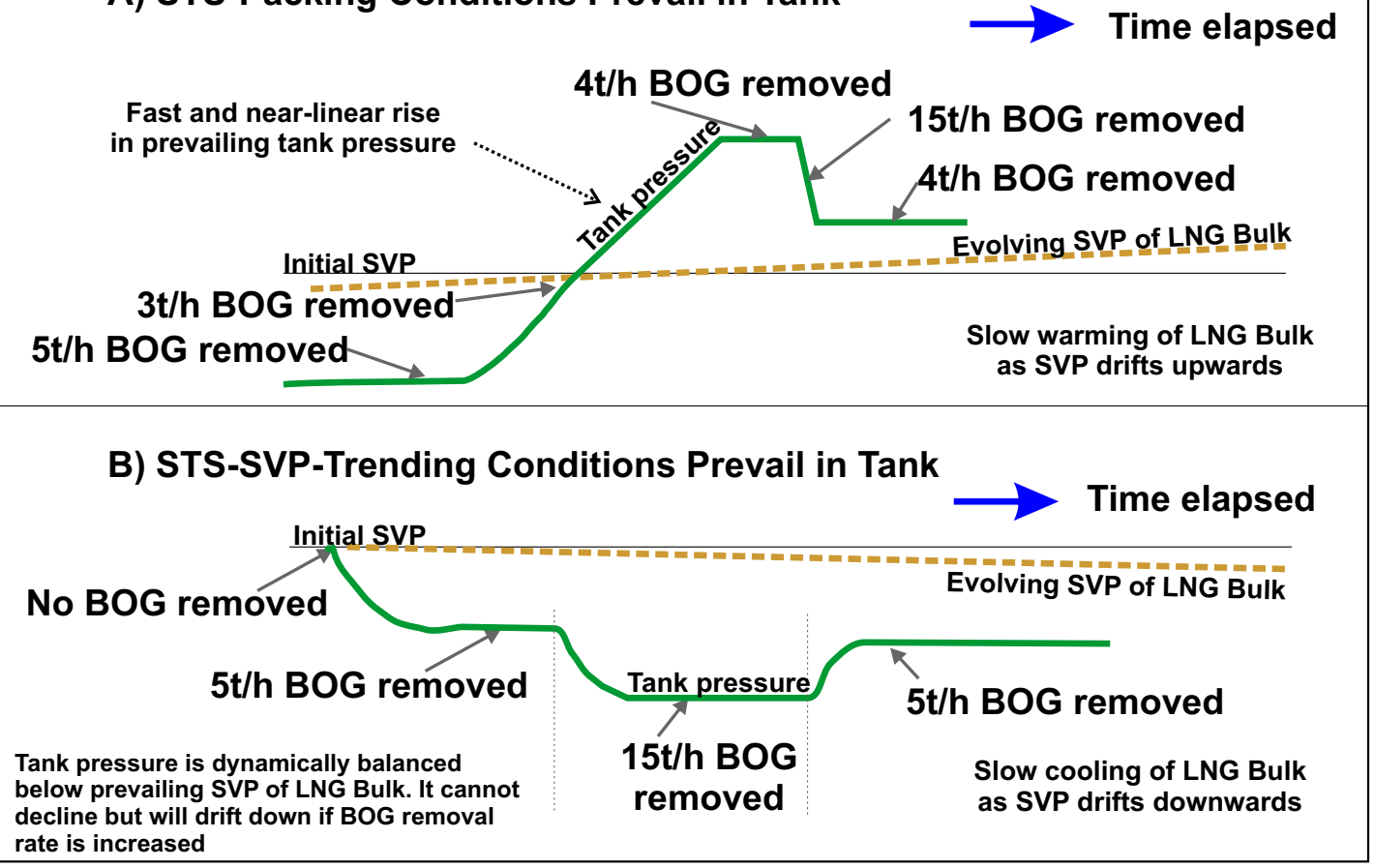

Fig. 13. Principal difference between tank-pressure responses relative to the SVP demarcation line (SVP of the LNG bulk or top-layer only in stratified conditions) during FSRU tank packing, depacking and SVP-trending conditions.

rated at 700 mbarg MARVS without extra boil-off removing capacity such as venting to an onshore flare. The normal BOG treatment capacity of an FSRU cannot cope with such rates of pressure increase.

The volumetric balances for this case are always positive unless STS transfer rates are below $3,000 \mathrm{~m}^{3} / \mathrm{h}$ where the FSRU's BOG handling capacity can maintain SVP-trending conditions.

Taking in account all of the described cases, it is possible to calculate evolving pressure trends based on volumetric balance only for packing conditions (prior to and during STS). All the SVP-trending conditions curves can be estimated broadly by characteristic curves, based on estimated final values of SVP due to compositional and temperature changes (Figs. 9a, $9 \mathrm{~b}$ and 10). Guidelines for establishing characteristic pressure curves related to STS transfers into STS-trending tanks are:

1) at the start of STS transfers tank pressure conditions are typically SVP-trending (i.e., up to 50 mbar below the SVP of the prevailing heel cargo on FSRU).

2) At STS full transfer rates, even if SVP-trending conditions remains, tank pressure tends to rebalance upwards, due to compression, by about 20-35 mbar for STS transfer up to $7,000 \mathrm{~m}^{3} / \mathrm{h}$ even if an SVP-trending condition remains.

3) During STS transfer ramp down to the end of the cargo transfer, the tank pressure rebalances downwards by about 20-35 mbar even if SVP-trending conditions persists.
Changes (2) and (3) related to STS start and STS stop events are only visible during SVP trending conditions. In such cases, where the SVP-trending condition prevails, actual tank pressure moves closer towards the SVP of the LNG bulk (but remains below the SVP of LNG bulk) compared to its state just before an STS transfer starts or after an STS transfer ends.

\subsection{Volumetric balance interpretations for packing and depacking conditions during STS transfers}

Volumetric balances for two distinct conditions likely to occur during typical STS transfers are evaluated.

A) Packing during STS transfer (Fig. 13A):

This can be expressed as Eq. (2), which is a special condition of Eq. (1):

$$
\Delta_{s t s}=V L_{1}-V L_{2}-V G_{1}-V G_{2}-V G_{4}
$$

where $V G_{3}$ is assumed to be approximately zero (or negligible). Also, the volume of BOG removed for extra control purposes $\left(V G_{4}\right)$ may also be zero or negligible.

The negative contributors are: Regasification volume $\left(V L_{2}\right)$, boil-off removal for engine-room fuel and recondenser $\left(V G_{1}\right)$ and vapor return to $\operatorname{LNGC}\left(V G_{2}\right)$.

These negative contributions have to offset the positive contribution of the STS transfer volumes $\left(V L_{1}\right)$. If the STS 


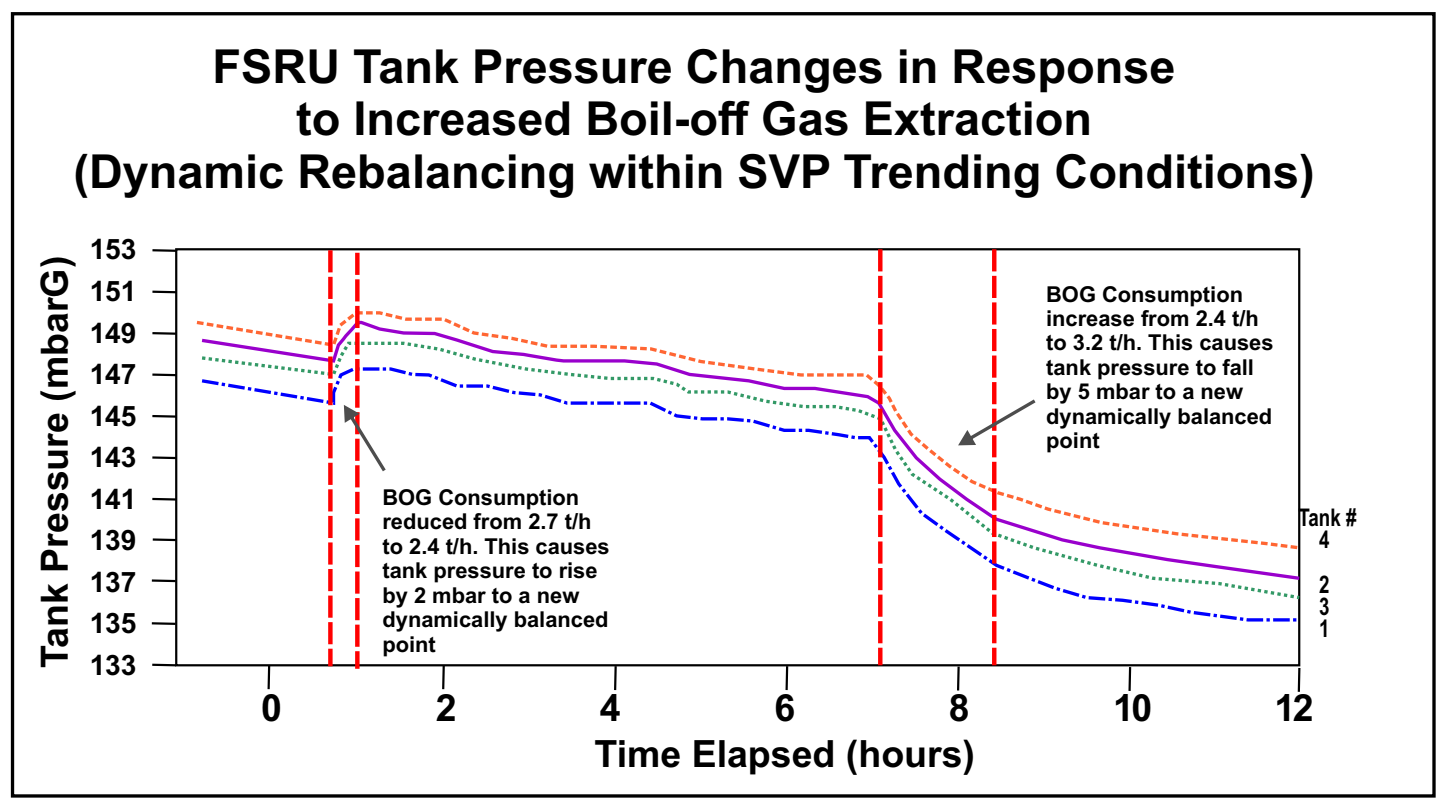

Fig. 14. Observed real case trends showing the impacts of reduced and increased BOG extraction on FSRU tank pressure trends.

transfer rate is too high, then to maintain FSRU tank pressure at a stable level the GCU or SD need to be operated to consume additional vapor removed from the tank(s). Natural boil-off-vapor generation is almost zero as a packed tank prevents vapor from evaporating through the LNG surface film. Consequently, the LNG bulk accumulates all heat ingress and warms up. 13):

B) Depacking or SVP-trending during STS transfer (Fig.

Eqs. (3) and (4), special conditions of Eq. (1), define these conditions:

Depacking case (Fig. 13A):

$$
\Delta_{s t s}=V L_{1}-V L_{2}-V G_{1}-V G_{2}-\left(V G_{4}\right)
$$

where $V G_{4}$ needs to be set just high enough to hold tank pressure at a safe level. If it is excessive then it would cause unnecessary BOG removal. If $V G_{4}$ is high eventually depacking ceases as tank pressure reaches the SVP of the LNG bulk. At that point, SVP-trending conditions will prevail (Section 2 Case 4).

SVP-trending case (Fig. 13B):

$$
\Delta_{s t s}=V L_{1}-V L_{2}-V G_{1}-V G_{2}+V G_{3}-\left(V G_{4}\right)
$$

where $V G_{3}$ is significant in Eq. (4), thus the volume of BOG removed for extra control purposes ( $V G_{4}$ "loss of cargo") should be held at zero to avoid stimulating unnecessary extra evaporation through the surface film that would waste cargo in GCU or SD when tank pressure falls below the LNG bulk's SVP.

The negative contributors to pressure are: Regasification volume $\left(V L_{2}\right)$; boil-off removal for engine-room fuel and recondenser $\left(V G_{1}\right)$; and, vapor return to $\operatorname{LNGC}\left(V G_{2}\right)$.

However, these negative contributions have to offset more positive contributions than in the packing case, because the natural and induced boil-off generation contribution $\left(V G_{3}\right)$ may vary from small to large volumes depending on operator's actions. Once FSRU tank pressure is dynamically floating below the SVP of the governing LNG, any additional or excessive removal of vapor (e.g., $V G_{4}$ ) from the tank will inadvertently drive more evaporation of vapor from that LNG. In such conditions, it is not appropriate to operate the GCU or SD equipment as it leads to significant cargo losses without good practical benefit (Fig. 7).

\section{Discussion}

\subsection{Practical calculations for predicting tank pressure curves for different types of STS transfer}

There are rare cases when STS transfer are performed without any BOG return to shore or back to the LNGC delivering the new cargo. Observations on some such cases have led to an empirical formula (Eq. (5)) that estimates the tank pressure rise on an hourly basis during tank packing conditions and tank pressure fall during depacking conditions for a range of tank pressures above the LNG bulk's SVP.

$$
P_{t+1}=P_{t}+\frac{\left(\Delta_{s t s}-\alpha\right)}{100} \frac{d P}{d t}
$$

where $P_{t}$ is the pressure during the current time period $t$ (usually a period of one hour); $P_{t+1}$ is the pressure during the next time period; $\Delta_{s t s}$ is the volumetric balance in $\mathrm{m}^{3} / \mathrm{h}$ calculated using Eq. (1) (or its special cases Eq. (2) to Eq. (4)); $\alpha$ is a volumetric balance correction that is specific to certain types of STS transfer conditions (see examples), $\alpha$ represents a "zero offset" adjustment; and $d P / d t$ is the tank pressure change rate established empirically from multiple observed FSRU STS transfers for the range of STS transfer conditions typically encountered. It is expressed as the average upward 


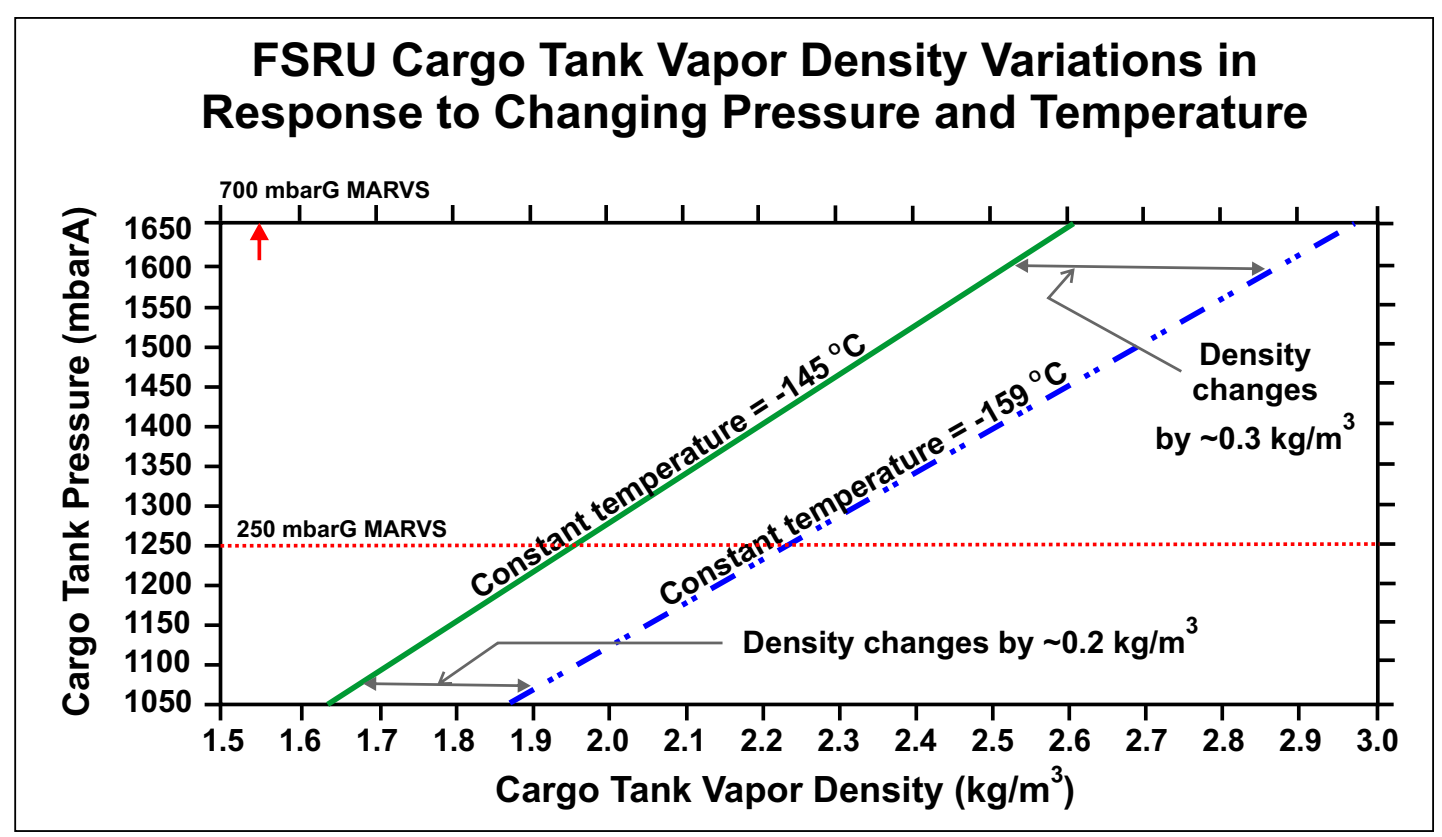

Fig. 15. Density of LNG tank vapor versus actual tank pressure for FSRU with 250 and 700 mbarg MARVS tanks comparing two specific vapor temperatures.

change (in the conditions considered) of pressure per hour for every $100 \mathrm{~m}^{3} / \mathrm{hrs}$ of volumetric balance.

Eq. (1) provides the sign $(+$ or - ) of the volumetric balance. Eq. (5) is only able to calculate pressure change if the actual tank pressure is above the SVP of the LNG bulk. Observations of STS transfers to FSRU suggest the average values appropriate for Eq. (5) are:

1. STS Stratification plus Packing Case 4 (Fig. 12) (20 observed STS transfers):

a) FSRU tank pressure should increase by approximately +1.8 mbar per every $100 \mathrm{~m}^{3} / \mathrm{h}$ of positive volumetric balance. In a depacking case with tank pressure above the SVP of the bulk LNG, when the volumetric balance is negative, tank pressure will decrease at approximately the same rate (i.e., -1.8 mbar per every $100 \mathrm{~m}^{3} / \mathrm{h}$ of negative volumetric balance over the increment of tank pressure above SVP of the LNG bulk).

b) the $\alpha$ balance correction for a specific type of STS takes into account the condensation effect. It corrects to the point where the volumetric balance achieves approximately constant FSRU tank pressure. For this STS transfer condition, the value of $\alpha$ is about -170 $\mathrm{m}^{3} / \mathrm{h}$.

c) FSRU tank pressure rise at zero volumetric balance is $+2.15 \mathrm{mbar} / \mathrm{h}$.

2. STS Mix plus Packing Case 2 (Fig. 12) (10 observed STS transfers):

a) FSRU tank pressure should change (up or down) by 1.5 mbar per hour per every $100 \mathrm{~m}^{3} / \mathrm{h}$ of volumetric balance, with same sign as volumetric balance.

b) the $\alpha$ balance correction is about $+190 \mathrm{~m}^{3} / \mathrm{h}$ to maintain FSRU tank pressure approximately constant.

c) FSRU tank pressure change at zero volumetric balance is $-1.36 \mathrm{mbar} / \mathrm{h}$.
Eq. (5) provides tank pressure estimates to an accuracy of approximately \pm 30 mbar. Consequently, to apply it to estimate a pressure increase from the start of an STS transfer and through its ramp-up phase to full transfer rate the pressure difference involved needs to be at least +25 to +35 mbar for rebalancing (not taking into account the effects of Eq. (5)). On the other hand, to apply Eq. (5) to estimate a pressure decrease during the ramp down from peak STS transfer rate to the end of the STS transfer, the pressure difference involved needs to be at least -25 to -35 mbar for rebalancing.

The volumetric balance and Eq. (5) need to be evaluated at the prevailing tank conditions to achieve the best accuracy for tank pressure trends. This means taking into account any changes in tank/LNG conditions as they occur during an STS transfer. The problem is that tank conditions may change continuously as various volumes are being added (STS inflow) and removed (LNG to regasification; BOG to recondenser, engine room and GCU/SD). Consequently, the volume of vapor in the FSRU tank's vapor space needs to be continuously recalculated to establish the instantaneous vapor volume and predict future tank pressure changes. Clearly, if the FSRU recondenser is operating and consuming $5 \mathrm{t} / \mathrm{h}$ of vapor from the tanks, the conditions of that vapor (density and temperature) will be quite different for a tank at a pressure of 120 mbarg compared to that in a tank at 450 mbarg. It is therefore necessary to continuously establish natural gas vapor-density changes caused by changing tank pressure and temperature conditions as an STS transfer proceeds (Fig. 15).

In SVP-trending conditions (including mixed and stratified cargoes), the approximate tank pressure trend can be readily extrapolated graphically from characteristic curves (Figs. 9a, $9 \mathrm{~b}$ and 10) without recourse to Eq. (5). At the beginning and end of any STS transfer there are rebalancing changes in tank pressure: 


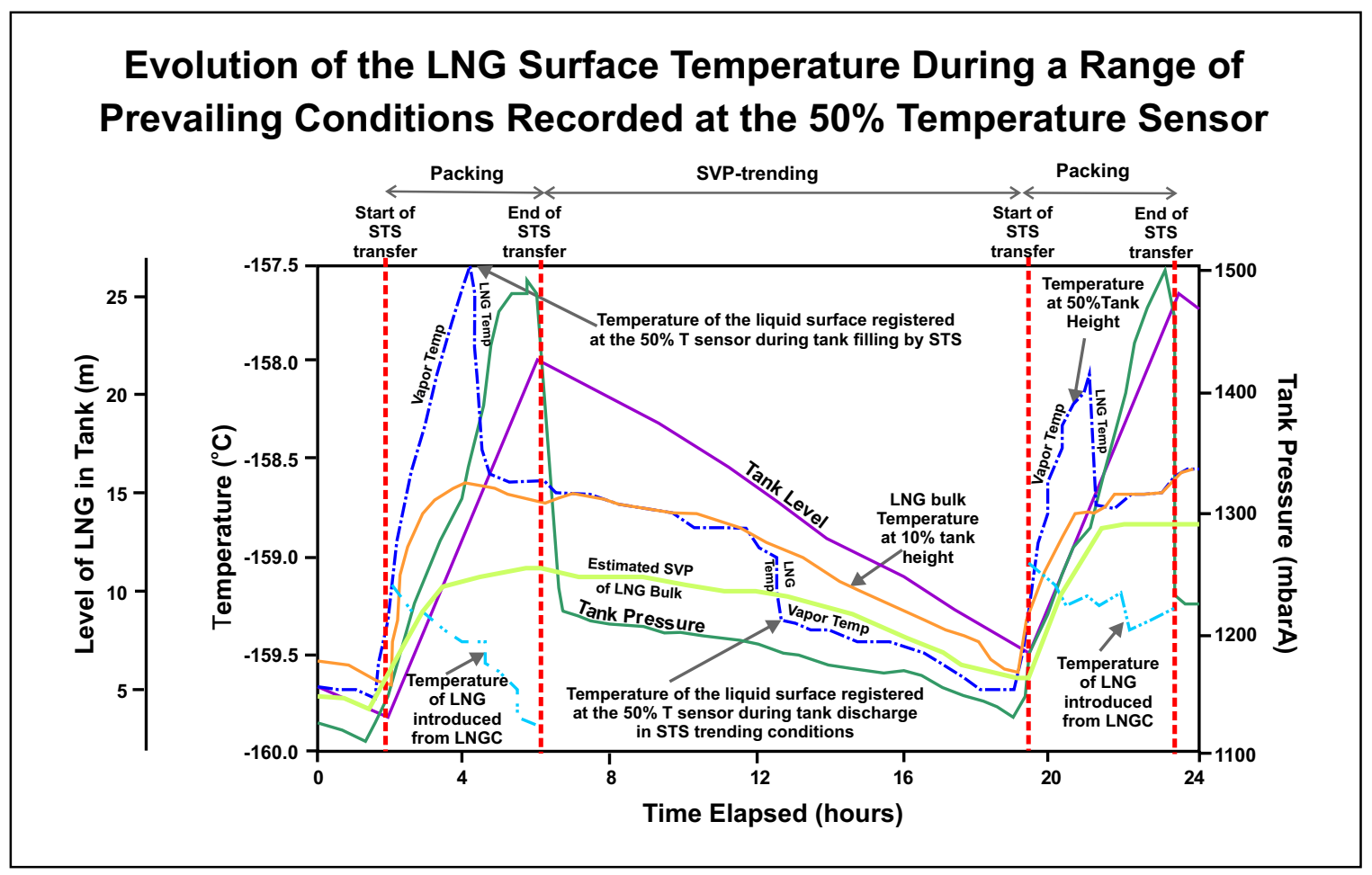

Fig. 16. Temperature records at the $10 \%$ and $50 \%$ temperature sensor in an FSRU tank for STS Mix with packing conditions during STS transfers and SVP-trending between STS transfers. The 50\%-sensor temperature trend varies between the vapor space, surface LNG film and LNG bulk.

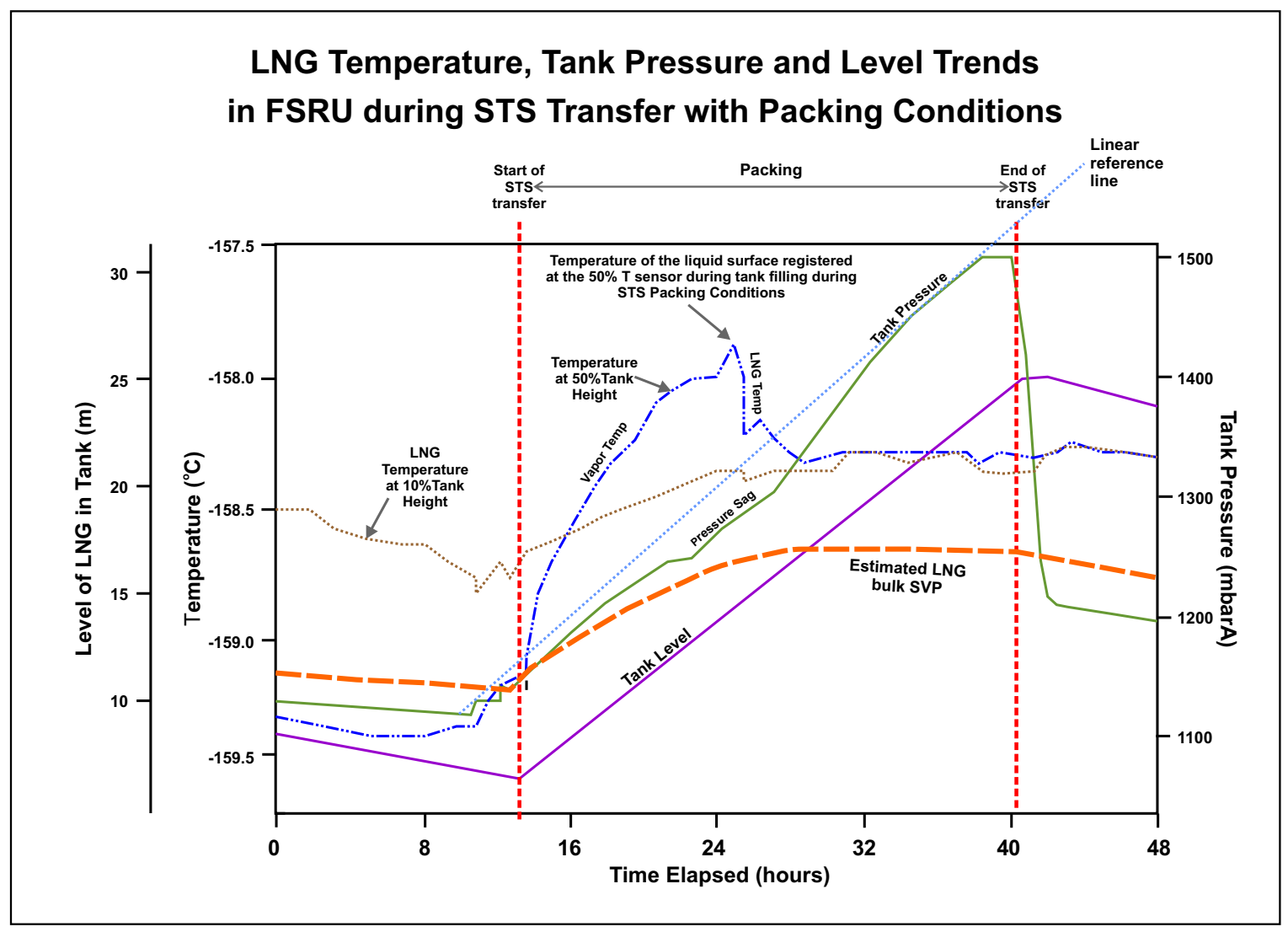

Fig. 17. Temperature records at the $10 \%$ and $50 \%$ temperature sensor in an FSRU tank for STS mix with packing conditions where the LNG film (causing tank pressure sagging) is slightly disrupted by emerging new cargo as there is a slight density difference between newly loaded cargo and the former LNG heel. 


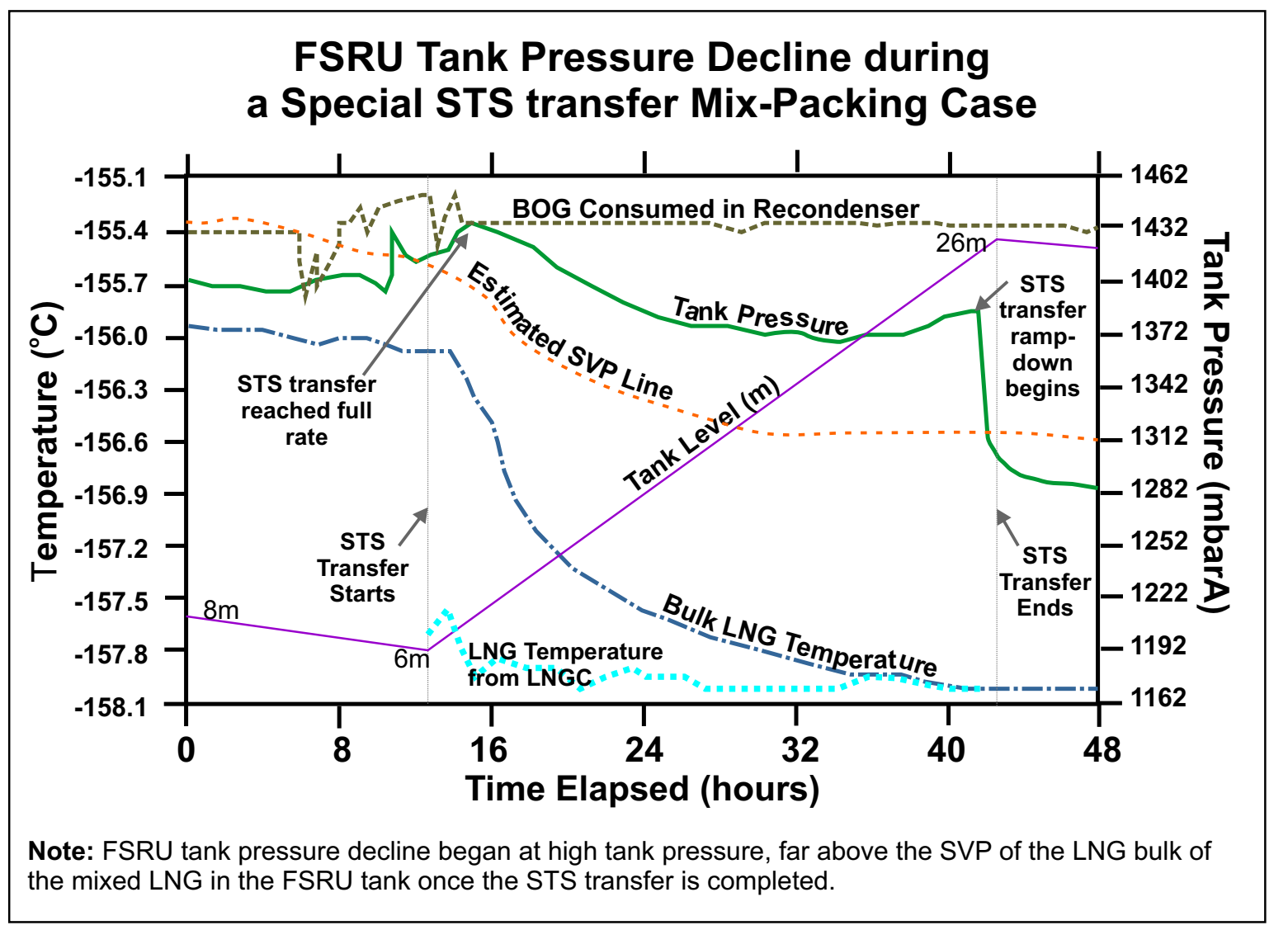

Fig. 18. FSRU tank pressure and temperature responses when LNG surface film is severely disturbed by emerging new cargo and leads to enhanced condensation on surface of vapor from the tank vapor space. There is a large density difference between the newly loaded cargo and the former LNG heel.

Distinct STS mix and STS stratification pressure trends should be anticipated for SVP-trending conditions based on the estimated SVP of the newly loaded LNG and estimated SVP of the cargo heel already present on the FSRU. Account also needs to be taken of the heating up of the LNG during STS transfer (Appendix B). During stratification more precise data is available as the former heel cargo becomes the top LNG layer that governs tank pressure. For STS conditions the final SVP of LNG bulk at the end of the STS transfer can be estimated using the weighted averages of mass, temperature and composition for the former heel and newly loaded cargo masses. The SVP of the bulk LNG can be calculated using fluid thermodynamic software (e.g., Reference Fluid Thermodynamic and Transport Properties Database (NIST /REFPROP, 2019) using estimated compositions. This defines the SVP of the LNG bulk for a range of temperatures enabling tank pressure curve constructed following the characteristic curves for the conditions (Figs. 9a and 9b).

In cases of STS transfers where BOG from the FSRU tanks is returned to the LNGC from which the LNG delivery is taking place, then Eq. (5) can be beneficially applied. It can either calculate the approximate minimum return BOG flow required to maintain FSRU tank pressure constant or estimate the resulting FSRU maximum pressure to expect at full transfer rate taking account of all relevant variables including STS transfer rate. In such cases, estimates of the tank pressure expected in FSRU tanks, can be approximated by applying the general Bernoulli equation (Munson et al., 2013; LMNO Engineering, 2019) (Appendix C).

\subsection{Tank pressure evolution where the LNG surface film is continuously disrupted}

This addresses the film conditions described in Section 2 Cases $4 \mathrm{a}$ and $4 \mathrm{~b}$. Temperature profiles across the LNG liquid surface film are readily recorded as that film passes temperature sensors at specific levels in the tank. Two typical temperature trends associated with the surface film are evaporation prevailing (Fig. 16) and condensation prevailing (Figs. 16 and 17), where pressure curves display sagging to various degree (with non-linearity in the packing case). Comparison of these two temperature records reveals that the temperature of the LNG bulk immediately below the surface film, and within the film itself, are lower when evaporation takes place (Fig. 16). Once the tank vapor space is physically pressurized (packed) by the STS transfer operation, then the temperature of the surface film becomes warmer than the LNG bulk beneath it (Fig. 16). Observations show that temperatures in the vapor space just above the LNG liquid surface film, and in the film itself, can vary from warmer than the LNG bulk to colder than the LNG bulk.

An observed STS transfer case (Fig. 18), took place in se- 
vere packing conditions yet instead of tank pressure rising, as would typically be expected, tank pressure trended downwards by 70 mbar during the STS transfer. Pressure fell an additional 90 mbar when the STS transfer terminated. This atypical tank pressure behaviour during an STS is related to very specific and unusual prevailing conditions:

- FSRU high tank pressure at the start of STS transfer was high ( 420 mbarg).

- The heel in the FSRU tank was heavy LNG (highdensity).

- Very light (low-density) and very cold LNG $\left(-160.6^{\circ} \mathrm{C}\right)$ was delivered by the LNGC.

New LNG introduced into the FSRU tanks rapidly upwelled through the heel cargo due to its much lighter density. It appears to have disrupted the surface film continuously and severely. Consequently, excessive condensation of vapor from the vapor space occurred at the surface of LNG, because new emerging LNG at the liquid surface (through a broken surface film) was much colder and the prevailing tank pressure was much higher than the SVP of that emerging surface LNG. A situation emerged such that packing directly enhances condensation of vapor at freshly exposed LNG at the liquid surface in the absence of a film.

\section{Conclusions}

The behaviours described in this paper are determined by the saturated vapor pressure (SVP) of the LNG bulk, surface film conditions and external processes conducted. Formulaic relationships approximate pressure duality helping to improve FSRU tank management system and reduce onboard gas consumption thus saving cargo for extra benefit.

In this paper, the analysis of typical STS transfer tankpressure trends together with volumetric balance calculations enables tank pressure trends to be estimated for every $100 \mathrm{~m}^{3} / \mathrm{h}$ of volume change within a FSRU tank. This also facilitates estimation of future tank pressure curves during STS transfers. Formulaic relationships also provide useful estimates of the minimum quantity of boil-off gas to return to the LNGC during an STS transfer to maintain desirable FSRU tank conditions. Understanding and modelling LNG tank pressure duality, as well as general awareness of the phenomenon, is essential for effective and flawless FSRU cargo operations.

\section{Acknowledgement}

This study has benefited from detailed observations of more than 30 ship-to-ship LNG cargo transfers to floating storage and regasification units.

\section{Conflict of interest}

The authors declare no competing interest.

Open Access This article, published at Ausasia Science and Technology Press on behalf of the Division of Porous Flow, Hubei Province Society of Rock Mechanics and Engineering, is distributed under the terms and conditions of the Creative Commons Attribution (CC BY-NC-ND) license, which permits unrestricted use, distribution, and reproduction in any medium, provided the original work is properly cited.

\section{References}

Arjomandnia, P., Tade, M.O., Pareek, V., et al. Analysis of available data from liquefied natural gas rollover incidents to determine critical stability ratios. AIChE J. 2013, 60(1): 362-374.

Bates, S., Morrison, D.S. Modelling the behaviour of stratified liquid natural gas in storage tanks: A study of rollover phenomenon. Int. J. Heat Mass Trans. 1997, 40(8): 18751884.

Baudouy, B. Heat transfer and cooling techniques at low temperature. arXiv: 1501.07153 [physics.acc-ph], 2015.

Booth, D.A., Bulsara, A., Joyce, F.G., et al.. Wall film flow effects with liquefied natural gas. Cryogenics 1974, 14(10): 562-563.

Chen, Y.G., Price, W.G., Temarel, P. Numerical simulation of liquid sloshing in LNG tanks using a compressible twofluid flow model. Paper ISOPE-I-09-532 Presented at the International Offshore and Polar Engineering Conference, Osaka, Japan, 21-26 July, 2009.

Deshpande, K.B., Zimmerman, W.B., Tennant, M.T., et al. Optimization methods for the real-time inverse problem posed by modelling of liquefied natural gas storage. Chem. Eng. J. 2011, 170(1): 44-52.

Dimopoulis, G., Frangopoulos, C. A dynamic model for liquefied natural gas evaporation during marine transportation. Int. J. Thermodyn. 2008, 11(3): 123-131.

Dobrota, D., Lalić, B., Komar, I. Problem of boiloff in LNG supply chain. Trans. Marit. Sci. 2013, 2(2): 91-100.

GIIGNL. Rollover in LNG Storage Tanks. 2nd Edition, 20122015/Public Version, 2012.

Globe, S., Dropkin, D. Natural convection heat transfer in liquids confined by two horizontal plates and heated from below. J. Heat Trans. 1959, 81(1): 24-28.

Glomski, P., Michalski, R. Problems with determination of evaporation rate and properties of boiloff gas on board LNG carriers. J. Polish CIMAC 2011, 6(1): 133-140.

Grotle, E.L., Esoy, V. Dynamic modelling of the thermal response enhanced by sloshing in marine LNG fuel tanks. Appl. Therm. Eng. 2018, 135(5): 512-520.

Hashemi, H.T., Wesson, H.R. Cut LNG storage costs. Hydrocarb. Process. 1971, 50(1): 246-249.

Hayashi, K., Yarimizu, K., Furutani, S. Supercompact BOG recondensing system minimizes equipment lifecycle costs. World Oil 2016, 237(10): 41-44.

Kanazawa, T., Kazuhiko, K., Kuroda, A., et al. Experimental study on heat and fluid flow in LNG tank heated from the bottom and sidewalls. Heat Trans. Asian Res. 2004, 33(7): 417-430.

Kim, H., Shin, M.W., Yoon, E.S. Optimization of operating procedure of LNG storage facilities using rigorous BOR model. Paper Presented at the Proceedings of the 17th World Congress The International Federation of Automatic Control, Seoul, Korea, 6-11 July, 2008.

Kulitsa, M., Wood, D.A. LNG Cargo Handling-Conclusion: Tandem pressures between ships during STS transfers cuts gas losses. Oil Gas J. 2017a, 115(12): 65-70.

Kulitsa, M., Wood, D.A. LNG Cargo Handling: New approach 
improves ship-to-ship LNG transfers. Oil Gas J. 2017b, 115(11): 56-60.

Kulitsa, M., Wood, D.A. LNG rollover challenges and their mitigation on Floating Storage and Regasification Units: New perspectives in assessing rollover consequences. J. Loss Prevent. Proc. Ind. 2018a, 54: 352-372.

Kulitsa, M., Wood, D.A. Floating storage and regasification units face specific LNG rollover challenges: Consideration of saturated vapor pressure provides insight and mitigation options. Nat. Gas Ind. 2018b, 5(4): 391-414.

Kulitsa, M., Wood, D.A. Soft metal blanket with optional antisloshing conceptual designs to improve pressure control for floating and land-based liquefied natural gas tanks. Adv. Geo-Energy Res. 2019, 3(4): 424-447.

Laciak, M. Liquefied natural gas storage of variable composition. Arch. Min. Sci. 2015, 60(1): 225-238.

Lemmon, E.W., Huber, M.L., McLinden, M.O. NIST reference fluid thermodynamic and transport properties-REFPROP. Version 10, 2019.

Li, Y., Chen, X., Chein, M.H. Flexible and costeffective optimization of BOG (boil-off gas) recondensation process at LNG receiving terminals. Chem. Eng. Res. Des. 2012, 90(10): 1500-1505.

LMNO Engineering. Bernoulli Equation Calculator with Applications, 2019.

Ludwig, C., Dreyer, M.E., Hopfinger, E.J. Pressure variations in a cryogenic liquid storage tank subjected to periodic excitations. Int. J. Heat Mass Trans. 2013, 66: 223-234.

Munson, B.R., Young, D.F., Okiishi, T.H. Fundamentals of Fluid Mechanics. New York, USA, John Wiley and Sons, 2013.

Paine, S.N., Turner, D.D., Kuchler, N. Understanding thermal drift in liquid nitrogen loads used for radiometric calibration in the field. J. Atmos. Ocean Technol. 2014, 31(3): 647-655.
Prandtl, L. Über Flüssigkeitsbewegung bei sehr kleiner Reibung, Verhandlungen des Dritten Internationalen Mathematiker-Kongresses (Heidelberg 1904), 1905, pp. 484-491.

Roh, S., Son, G. Numerical study of natural convection in a liquefied natural gas tank. J. Mech. Sci. Technol. 2012, 26(10): 3133-3140.

Rudman, M., Prakash, M., Cleary, P.W. Simulation of liquid sloshing in a model LNG tank using smoothed particle hydrodynamics. Paper ISOPE-I-09-540 Presented at the International Offshore and Polar Engineering Conference, Osaka, Japan, 21-26 June, 2009.

Scurlock, R.G. Stratification, Rollover and Handling of LNG, LPG and Other Cryogenic Liquid Mixtures. United Kingdom, Springer International Publishing, 2016.

Sha, W., Ren, J., Wang, C., et al. Dynamic characteristics of the initial interface in stratified multi-composition liquid tanks during rollover. Appl. Therm. Eng. 2018, 145: 396406.

Weyburne, D. A mathematical description of the fluid boundary layer. Appl. Math. Comput. 2006, 175(2): 16751684.

Weyburne, D. New thickness and shape parameters for describing the thermal boundary layer. arXiv: 1704.01120 [physics.flu-dyn], 2017.

Wood, D.A., Kulitsa, M. A review: Optimizing performance of Floating Storage and Regasification Units (FSRU) by applying advanced LNG tank pressure management strategies. Int. J. Energy Res. 2018, 42(4): 1391-1418.

Zakaria, Z., Kamarulzaman, K., Samsuri, A. Rollover phenomena in liquefied natural gas storage: Analysis on heat and pressure distribution through CFD simulation. Int. J. Innov. Eng. Technol. 2017, 8(1): 392-400. 


\section{Appendix A: Case showing impacts of tank pressure duality}

This observed STS transfer case reveals how duality of tank pressure behaviour practically affects the way tank pressure states evolve and pressure trends can meaningfully be interpreted during FSRU operations. Consider a tank at 1,250 mbarA pressure and containing LNG, assuming it is in a transient/static state (i.e., no STS transfer taking place, no BOG extraction, no cargo operations). The LNG surface film and the LNG bulk would have the same temperature and SVP and the tank pressure would equal the SVP of the LNG bulk (Section 2). Condensation equals evaporation at the surface film (an equilibrium state prevails).

If a large mass of BOG is evacuated from the vapor space continuously the pressure state of the tank changes. Evaporation excess from the surface film causes its temperature to drop rapidly (within about 30 minutes) by up to about $0.35{ }^{\circ} \mathrm{C}$. The colder LNG on the liquid surface has lower SVP causing tank vapor pressure to reduce adjusting to this lower SVP (i.e., in this case, dropping by about $35 \mathrm{mbar}$ to $1,215 \mathrm{mbarA}$ ). That tank pressure is maintained dynamically below the SVP of the LNG bulk liquid (1,250 mbarA) by continuous removal of BOG.

If the BOG mass-removal rate is increased, then evaporation through the surface film will increases proportionally to counteract the pressure change that induces. The surface film cools further establishing a new SVP (within about 30 minutes) causing actual tank pressure to fall to $1200 \mathrm{mbarA}$ (a new equilibrium pressure condition for the film). This point is dynamically countered by the SVP of the LNG bulk, preventing tank pressure falling further. If heat removed by evaporation is higher than heat ingress then the temperature of the LNG bulk declines, but much more slowly than SVP changes to the surface film. The SVP of the surface film changes almost immediately in contrast to the slower changes to the SVP of the LNG bulk (Figs. 4 and 13).

If BOG removal rate then returns to its initial value, tank pressure rapidly establishes equilibrium with LNG film again at $1,215 \mathrm{mbarA}$. If all processes are subsequently halted, then tank pressure returns rapidly to static/transient conditions (i.e., 1250 mbarA).

If STS transfer rates fill the FSRU tank more rapidly, and BOG removal is not able to compensate for tank vapor space volume reduction, the pressure state of the tank changes in the opposite direction to that previously considered. Tank vapor is physically compressed (Section 2 Case 3a). The surface film dynamically equilibrates with rising tank pressure and adjusts its SVP accordingly to match higher tank pressure. Meanwhile, the SVP of LNG bulk remains for some time at 1,250 mbarA, but very slowly warms up towards an SVP 1,700 mbarA. Such a change to the LNG bulk is likely to take days and be obscured by the rapid, near-linear increase in tank pressure up to 1,700 mbarA. While the SVP of the LNG film also rises rapidly to 1,700 mbarA, the SVP of LNG bulk remains for many hours at or just above 1,250 mbarA.

Once the STS transfer described ends, with BOG removal continues at the same constant rate, tank pressure quickly declines near-linearly back towards $1,250 \mathrm{mbarA}$, followed closely by the SVP of the surface film. At 1,250 mbarA the tank pressure pattern changes (Section 2, Case 3b) becoming held dynamically again at its initial 1,215 mbarA state (Figs. 4, 7 and 13).

\section{Appendix B: LNG heating during STS transfers}

LNG in a tank is heated by energy input from the pumps, by friction in the pipework (particularly the transfer line), by heat entering through the pipework (induced heat) and by heat ingress through the tank wall/insulation. Thus, the heating of LNG introduced during an STS transfer to an FSRU averages about $+1.0^{\circ} \mathrm{C}$, divided into two components:

i) Heating associated with the STS pipework, LNGC pumps, and transfer pumps occurring prior to the LNG entering FSRU main liquid header and reaching tank piping. Based on STS transfer observations this heating component contributes about +0.4 to $+0.5{ }^{\circ} \mathrm{C}$ to the LNG temperature for STS transfers conducted at rates between 5,000 and $7,000 \mathrm{~m}^{3} / \mathrm{h}$. However, in rare cases where the transfer lines are very long (e.g., about $1 \mathrm{~km}$ in some dock-side-STS transfers) that temperature increase could rise to $+0.7^{\circ} \mathrm{C}$ or more.

ii) Heating of the LNG occurring on its pathway into the FSRU tanks (i.e., vertical fall, distribution, etc.) and associated FSRU piping during the STS transfer. Based on STS transfer observations this heating component contributes about +0.4 to $+0.6{ }^{\circ} \mathrm{C}$ to the LNG temperature for STS transfers conducted at rates between 5,000 and $7,000 \mathrm{~m}^{3} / \mathrm{h}$.

Observed STS transfers to FSRU recorded temperature increases ranging from $+0.7{ }^{\circ} \mathrm{C}$ (faster transfer rates) to $+1.1{ }^{\circ} \mathrm{C}$ (slower transfer rates) at LNG transfer rates of between 5,000 and $7,000 \mathrm{~m}^{3} / \mathrm{h}$ via loading arms or flexible hoses. Empirical observations indicate that for every $+0.1{ }^{\circ} \mathrm{C}$ temperature increase to the LNG bulk there is an approximate tank pressure increase (SVP of LNG bulk) of about +10 mbar. A $+1.0{ }^{\circ} \mathrm{C}$ increase to LNG bulk temperature causes the SVP of the LNG bulk to rise by about 100 mbar for all commercial LNG grades involved. The heating rate of LNG in an FSRU tank during an STS transfer can be influenced to an extent by managing the use of FSRU equipment (Kulitsa and Wood, 2017a, 2018b; Wood and Kulitsa, 2018).

\section{Appendix C: Estimation of FSRU tank pressure resulting during STS transfer with BOG return}

In cases of STS transfers where BOG from the FSRU tanks is returned to the LNGC from which the LNG delivery is taking place, then Eq. (5) can be applied to calculate the approximate minimum return BOG flow required to maintain FSRU tank 
pressure constant. It can also be used to estimate the resulting FSRU pressure trend based on all relevant variables, including STS transfer rates. It does this by establishing the maximum FSRU tank pressure required to push the required BOG return flow to the LNGC.

In such cases, estimates of the tank pressure expected in FSRU tanks, can be approximated by applying the general Bernoulli equation (Munson et al., 2013; LMNO Engineering, 2019) (Eq. (C-1)).

$$
0=Z_{2}-Z_{1}+\frac{P_{2}-P_{1}}{\rho g}+\frac{V_{2}^{2}-V_{1}^{2}}{2 g}
$$

where:

$Z_{2}-Z_{1}=$ elevation difference (taken as 0 ) between tank outlet on the LNGC and tank inlet;

$P_{2}-P_{1}=$ pressure difference between FSRU tank and LNGC tank;

$P_{1}$ is pressure inside FSRU tank;

$P_{2}$ is pressure inside LNGC tank;

$V$ = fluid velocity;

$V_{1}=$ fluid velocity entering the FSRU tank, which is estimated as zero;

$V_{2}=$ gas velocity entering to LNGC tanks;

$\rho=$ fluid density, which in this case is transfer vapor density;

$g=$ acceleration due to gravity;

$Q=$ flow rate $=V_{1} A_{1}=V_{2} A_{2} ;$

$A=$ pipe cross-section area;

$A_{1}=$ vapor transfer pipe cross-section area leaving the FSRU tank, here STS transfer pipe, when all vapor valves are fully open;

$A_{2}=$ vapor transfer pipe cross-section area entering the LNGC tank, here STS transfer pipe, when all vapor valves are fully open;

If the pipework is circular $A=\pi D^{2} / 4$.

$D=$ circular pipe diameter (manifold).

The Bernoulli equation (Eq. (C-1)) may be simplified to provide approximate estimates of gas flow $(Q)$ (Eq. (C-2)) and FSRU tank pressure $\left(P_{1}\right)($ Eq. $(\mathrm{C}-3))$.

$$
Q_{\text {calc }}=V_{2} * \frac{\pi}{4} D^{2}=\sqrt{\left(\frac{2}{\rho} *\left(P_{1}-P_{2}\right)\right)} * \frac{\pi}{4} D^{2}
$$

with $Q$ (LNG volume transferred) $=Q_{\text {calc }}$ as a constraint (limit), Then:

$$
P_{1}=\frac{1}{2} * V_{2}^{2} * \rho+P_{2}
$$

or:

$$
P_{1}=P_{2}+Q^{2} * \rho * \frac{8}{\pi^{2} * D^{4}}
$$

Eqs. (C-1) to (C-4) do not take in account friction, bends in pipework piping, etc., so estimates generated using them tend to slightly overestimate pressure. They can be evaluated using an online calculator (Paine et al., 2014). An additional constraint, is that the volume of gas taken by LNGC cannot be greater than the volume of liquid pumped out of the LNGC tanks (otherwise the LNGC tank pressure would rise). Also, vapor heating occurs in the pipework (i.e., its temperature is raised to about minus 100 to minus $120^{\circ} \mathrm{C}$ from minus $155^{\circ} \mathrm{C}$ ) limiting accuracy.

If the estimated flow of vapor $(Q)$ to replenish the LNG pumped volume from the LNGC tanks is higher than the calculated vapor flow $\left(Q_{\text {calc }}\right.$, Eq. (C-2)), it implies that FSRU tank pressure would rise above the value $P_{1}$ input to Eq. (C-2). In this case, if the recalculated pressure $\left(P_{1}\right)$ approaches the maximum safe operatable tank pressure, then it indicates that the STS transfer rate is too high and should be reduced, or that additional gas consumption in the FSRU's CGU or SD should be initiated. The point at which both flows are equal $\left(Q=Q_{\text {calc }}\right)$ provides an approximate estimate of FSRU tank pressure. Eq. (C-4) can be used directly to calculate resulting FSRU tank pressure to assure given vapor flow (i.e., an estimated vapor flow rate to replenish the LNG volume pumped out of the LNGC tanks).

In other words, either maximum STS transfer rate can be verified, or maximum FSRU tank pressure estimated based on the required STS transfer rate. 